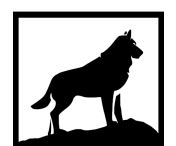

Michigan

Technological

1 8 8 5 University
Michigan Technological University

Digital Commons @ Michigan Tech

PETROPHYSICAL AND EMPIRICAL AND THEORETICAL ROCK PHYSICS MODELING FOR THE MOKI FORMATION IN TWO FIELDS IN THE TARANAKI BASIN, NEW ZEALAND

Deniz Yener

Michigan Technological University, dyener@mtu.edu

Copyright 2016 Deniz Yener

Recommended Citation

Yener, Deniz, "PETROPHYSICAL AND EMPIRICAL AND THEORETICAL ROCK PHYSICS MODELING FOR THE MOKI FORMATION IN TWO FIELDS IN THE TARANAKI BASIN, NEW ZEALAND", Open Access Master's Thesis, Michigan Technological University, 2016.

https://doi.org/10.37099/mtu.dc.etdr/117

Follow this and additional works at: https://digitalcommons.mtu.edu/etdr

Part of the Geophysics and Seismology Commons 


\title{
PETROPHYSICAL AND EMPIRICAL AND THEORETICAL ROCK PHYSICS MODELING FOR THE MOKI FORMATION IN TWO FIELDS IN THE TARANAKI BASIN, NEW ZEALAND
}

\author{
By \\ Deniz Yener \\ A THESIS \\ Submitted in partial fulfillment of the requirements for the degree of \\ MASTER OF SCIENCE \\ In Geophysics
}

MICHIGAN TECHNOLOGICAL UNIVERSITY

2016

(C) 2016 Deniz Yener 
This thesis has been approved in partial fulfillment of the requirements for the Degree of MASTER OF SCIENCE in Geophysics.

Department of Geological and Mining Engineering and Sciences

Thesis Advisor: $\quad$ Dr. Wayne D. Pennington

Committee Member: Dr. Roohollah Askari

Committee Member: Prof. Mir Sadri-Sabet

Department Chair: Dr. John S. Gierke 


\section{Table of Contents}

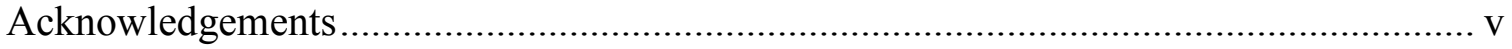

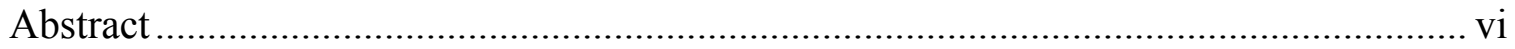

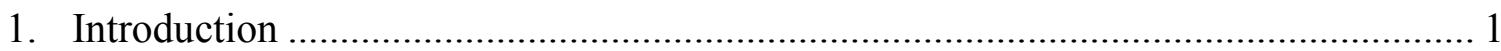

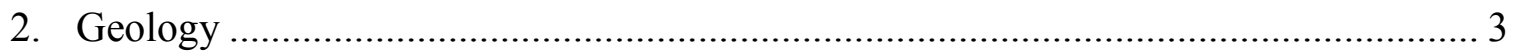

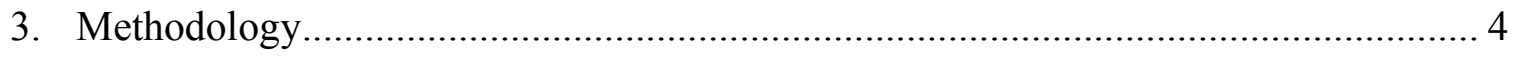

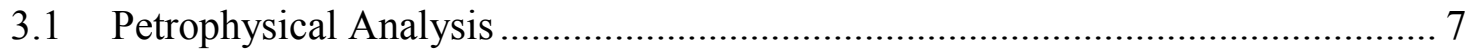

3.1.1 Crossplot Analysis and Mineral Identification ........................................ 7

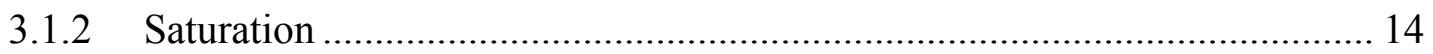

3.2 Sonic Prediction ................................................................................... 19

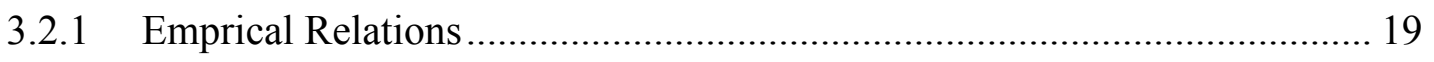

3.2.2 Rock Physics Model.......................................................................... 20

3.3 Fluid Substitution for Velocity Prediction ................................................. 30

3.3.1 Fluid Substitution in Shaley Sediment using Effective Porosity ................ 31

3.3.2 Practical Gassman Fluid Substitution in Sand/Shale Sequences ................. 33

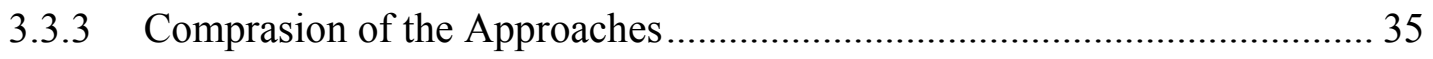

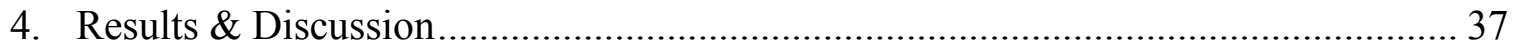

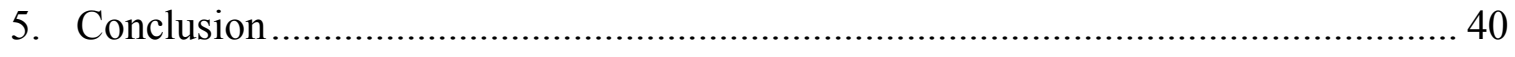

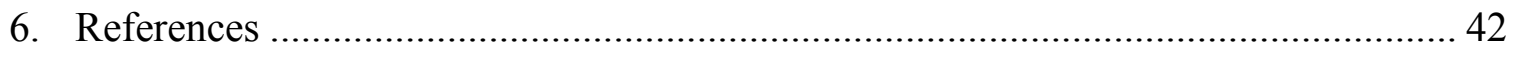

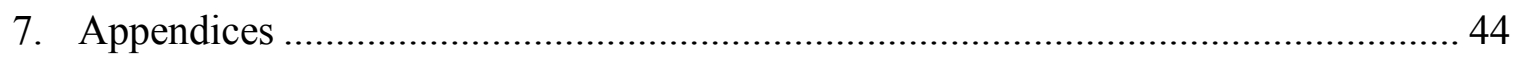




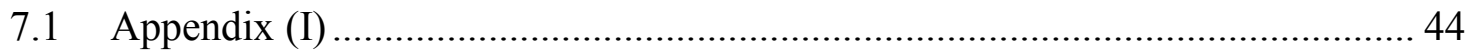

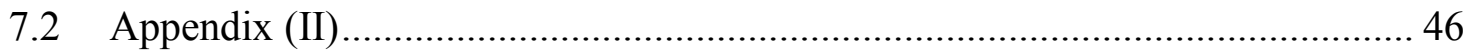

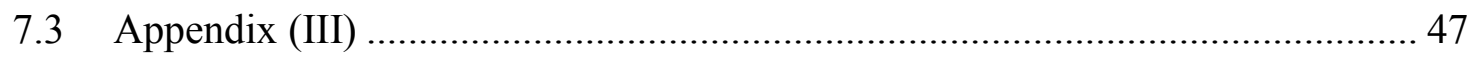

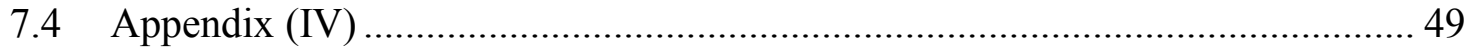

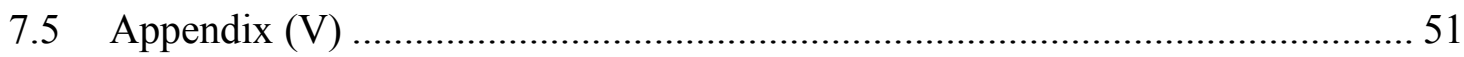

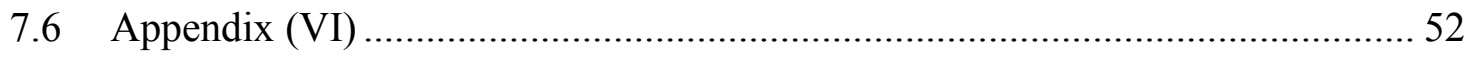

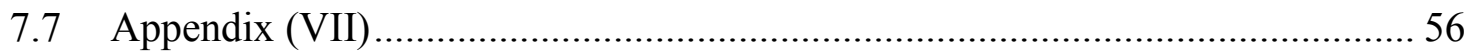

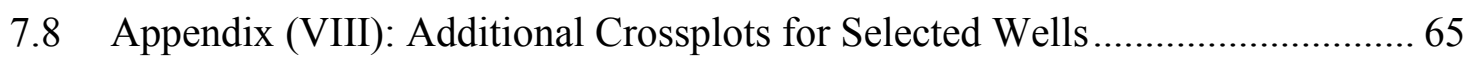

7.9 Appendix (IX): Lithologs of Moki-1 Well for Whole Depth Range .................. 69 


\section{Acknowledgements}

Being in the last step of having my Master's degree, I owe a debt of gratitude to those who have helped me through my education in Michigan Tech. Especially, I would like to thank to the person who has never stopped supporting me and has the biggest contribution in my career. I would not be able to improve my research skills in such extends. Thanks for all of your efforts and patience Dr. Wayne D. Pennington. I also would like to thank my committee members, Professor Mir Sadri-Sabet and Dr. Roohollah Askari, for their supports and contribution to shape my thesis into its final version.

I used the software, Interactive Petrophysics, provided by Senergy (A member of Lioyd's register group) in order to conduct this research, so I would like to thank it as well.

Finally, I must express my gratitude to my friends and family. All my friends, especially, Fatma Sinem Boyaci and Timucin Cakir, I appreciate your support and help for my graduation. My family always support and encourage me to do my best and I am very blessed to have them. Before finishing my sentences, I would like to thank to my boyfriend, Mustafa Aggul. I have infinitely many reasons to thank you. I could not finish my work without your love, support, and understanding. 


\begin{abstract}
This work consists of conventional petrophysical analysis and sonic response determination from empirical relations, rock physics modelling, and fluid substitution for six wells in the Moki formation of New Zealand's Taranaki Basin. The project composed of three parts encompassing conventional log analysis, rock-physics modeling using empirical and theoretical approaches, and finally rock-physics modeling for shaley sands using semi-empirical adaptations to Gassmann fluid substitution. Finally, comparisons are made between results for the different wells, based on their depths and mineralogy.
\end{abstract}

The first part of this study is presented as a petrophysical analysis, including crossplot analysis, conventional 3-mineral identification approach, and determination of water saturation profile, applied to several wells. After petrophysical analysis, we concluded that the Moki Formation may have well sorted grain size distribution or/and may be less compacted in the Tui Field than in the Maari Field although the formation is located at greater depths in the Tui Field. Furthermore, crossplot analysis indicates that these two fields have different types of clay; this may help explain the different compaction trends.

In the second part of this study, empirical relations and rock physics modelling were used for sonic response prediction. The P-wave velocity was predicted from the empirical Wyllie's Time Average equation and from the Kuster-Toksoz rock physics model. The Swave velocity was predicted from the empirical Greenberg-Castagna relation and from the Kuster-Toksoz rock physics model. 
After P-wave velocity predictions, we concluded that Kuster-Toksoz model works better in shale than Wyllie's Time Average equation due to the bound water in shale structure. This situation causes to have higher density response and to predict higher P-wave velocities calculated from Wyllie's Time Average equation in shale. Furthermore, less compaction in deeper depths causes to have higher porosity response; therefore, predicted P-wave velocities from Wyllie's Time Average equation are lower than P-wave velocities derived from sonic log. The Kuster-Toksoz model optimizes parameters in order to obtain best fit with the observed P-wave velocity derived from sonic log since the P-wave results from Kuster-Toksoz fit well for each field. We note that the Greenberg-Castagna model predicts a lower S-wave velocity than the Kuster-Toksoz model, expect in the highestvelocity streaks where limestone is likely present. Because there is no recorded an S-wave $\log$, the comparison is not reliable in this study.

In the last part of this study, Gassmann's equation was modified by using effective porosity for the sand-shale mixture. In order to estimate sonic velocities for different saturations, two different fluid substitution approaches were used: Dvorkin et al. (2007) and Simm (2007). The two methods yielded very similar results. 


\section{Introduction}

In the discovery of petroleum and natural gas resources, well-logging is an essential tool. It is a technology to measure physical, chemical, and lithological properties of the formations. Most of the properties of interest to development team are not measured directly. However, they are obtained from other measured such properties. Seismic velocity is one of these properties derived from sonic log. In the event of the unreliable or absent sonic logs, many approaches have been published manipulating other available data. Log data, petrophysical features of core data, and rock physics models have been commonly used in studies for the determination of sonic properties.

In this study, sonic response prediction was attempted on the basis of petrophysical analysis. In order to estimate the sonic response of Moki Formation, six different wells were selected from two different fields, Maari Field and Tui Field, in Taranaki Basin. These two fields are 40km away from each other, shown in Figure 3.1. The Moki Formation is found at different depth ranges in these fields and consists of sandstones with interbedded mudstones, siltstone, and limestone stringers (King (1988a, 1988b)).

Sonic velocities are affected by many factors other than simple porosity and lithology, including pore type. According to the Kuster-Toksoz (Kuster and Toksoz, 1974) method, pore types can be determined as penny-shaped ellipsoids of revolution, with aspect ratios representing ranging from spherical pores to fine-crack pores. Different minerals in the matrix exhibit different pore aspect ratio behavior. Xu and White (Xu and White, 1995) studied with combination of aspect ratios for mixed lithology. 
In order to specify the mineral composition, porosity, and water saturation profile of the formation, conventional petrophysical analysis was performed. To determine sonic response, empirical relationships and rock physics model, inspired by the mixed-lithology studies by Xu and White (1995), approaches were computed by using lithology, porosity, and other physical properties of the rock. Then the results obtained from empirical relations and rock physics model were compared with the observed P-wave velocity derived from sonic log and each other. The last part of this study, Gassmann's (1951) equation was modified for shaley sand to predict sonic velocities. At the end, we compare the all results for the Maari Field and the Tui Field based on the differences and similarities of petrophysical properties. 


\section{Geology}

King (1988a, 1988b) introduced "Waiti Group" as a name for most of the Miocene sedimentary succession in the Taranaki Basin. The Waiti Group is a regressive and dominantly clastic succession. Due to the tectonism of the Neogene converging plates, a large volume of rock was deposited in the Taranaki Basin during the Miocene age. The Waiti Group is composed of six formations: Manganui, Moki, Mohakatino, Mount Messenger, Urenui, and Ariki formations. The Moki formation is the subject of interest in this thesis (King (1988a, 1988b)).

The Moki formation is a turbidite complex in the southern and central parts of the Taranaki Basin. The formation is a secondary target and provides a significant amount of hydrocarbon. The formation is composed of sandstones with interbedded mudstones and siltstone and limestone stringers. The grain size of the sandstones are predominantly fine to very fine. The formation is located between the lower and middle Manganui formations which form a bathyal succession. Because of the nature of the formation, gamma ray readings are lower than those of the lower and upper Manganui formations, and readily identified on logs (King (1988a, 1988b))..

In this thesis, Maari Field and Tui Field were chosen for the analysis of the Moki formation. These two fields are $40 \mathrm{~km}$ away from each other and the Moki formation is found at different depth ranges in the two fields, at $1300-1600 \mathrm{~m}$ in the Maari field and $2700-2800 \mathrm{~m}$ in the Tui Field. 


\section{Methodology}

In order to determine sonic velocities of Moki Formation and apply fluid substitution on its log data, it is necessary to know its constituent mineral types, porosity, and fluid types in pores. These lithological properties are sensitive to locations of wells and depth range of the formation. In order to observe differences and similarities of such properties, we will consider two different fields, Maari Field and Tui Field, in Taranaki Basin. From each field, shown in Figure 3.1, we select three wells with regular suite of logs: gamma ray (GR), density (RHOB), neutron porosity (NPHI), sonic (DT), photoelectric absorption (PEF), deep lateralog (LLD), and shallow lateralog (LLS). In this section, conventional log analysis techniques were applied to the selected wells. Moki-1 well from Maari Field and Amokura-1 well from Tui Field were chosen to provide examples, and the remaining wells were presented in the Appendix (VIII). In Figure 3.2 and 3.3, well logs are displayed for Moki-1 and Amokura-1, respectively.

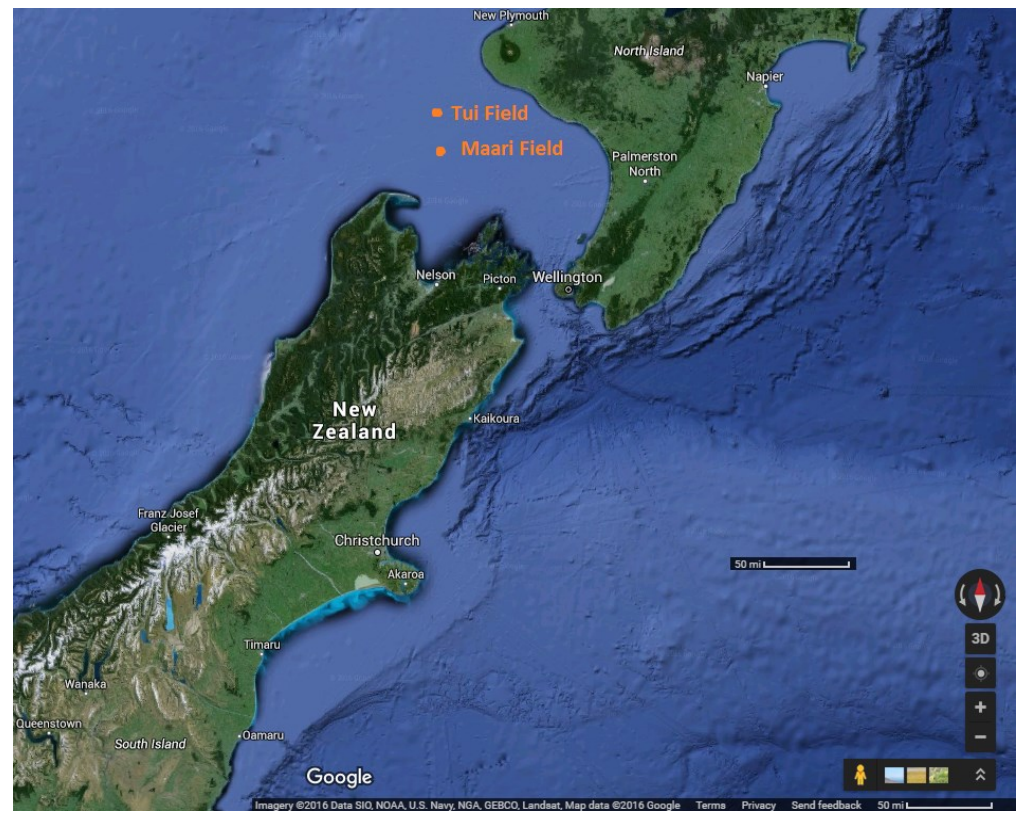

Figure 3.1. Field Location map (Google Maps, 2016). 


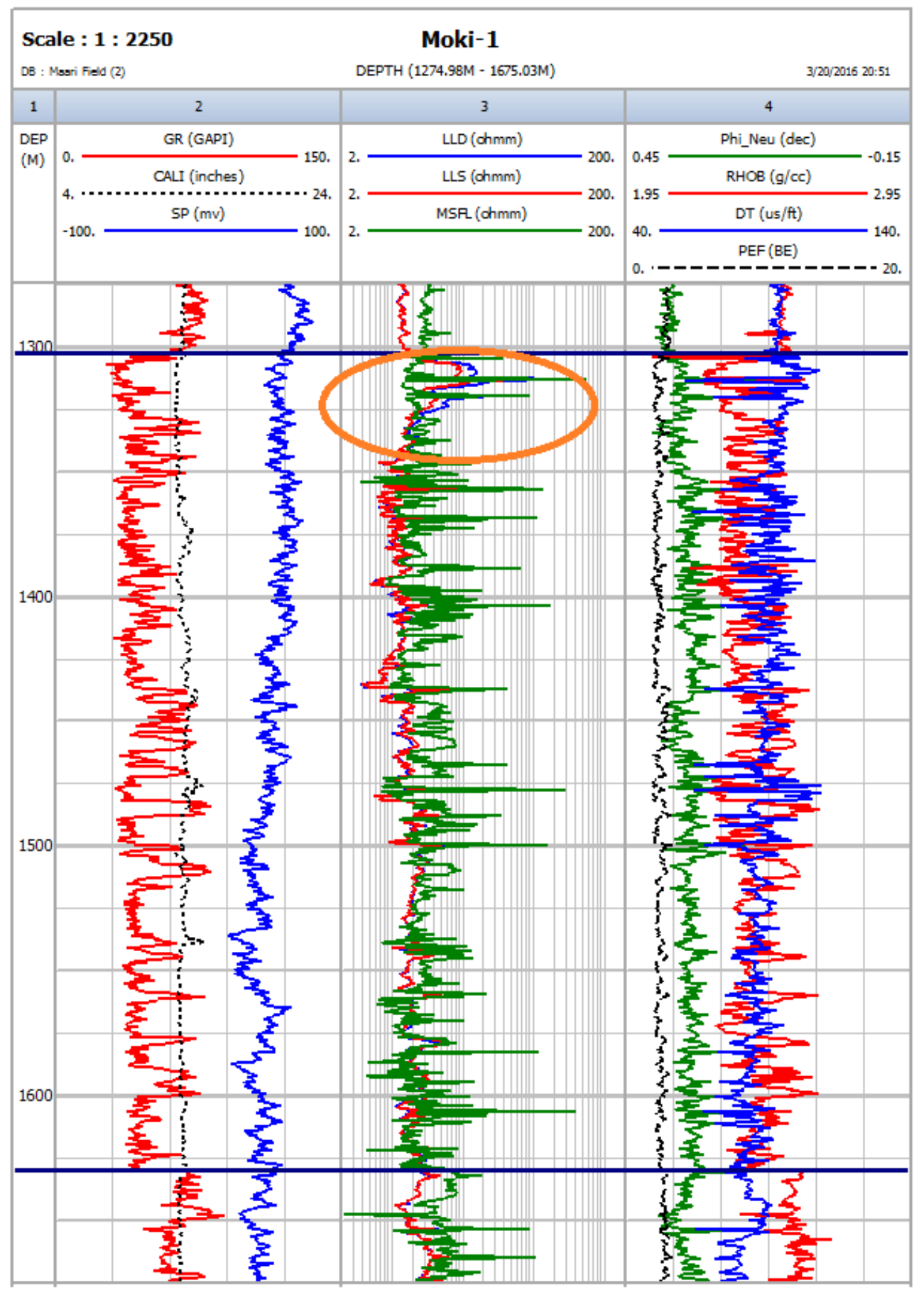

Figure 3.2. Litholog for Moki-1 well. The first track shows depth range. The second track displays gamma ray (red), caliper (black), and spontaneous potential (blue) logs. The third track represents resistivity logs: deep lateralog (blue), shallow lateralog (red), and microresistivity log (green). The fourth track identifies neutron (green), density (red), sonic (blue), and photoelectric absorption (black) logs. The orange circle in third track shows the potential hydrocarbon area. 


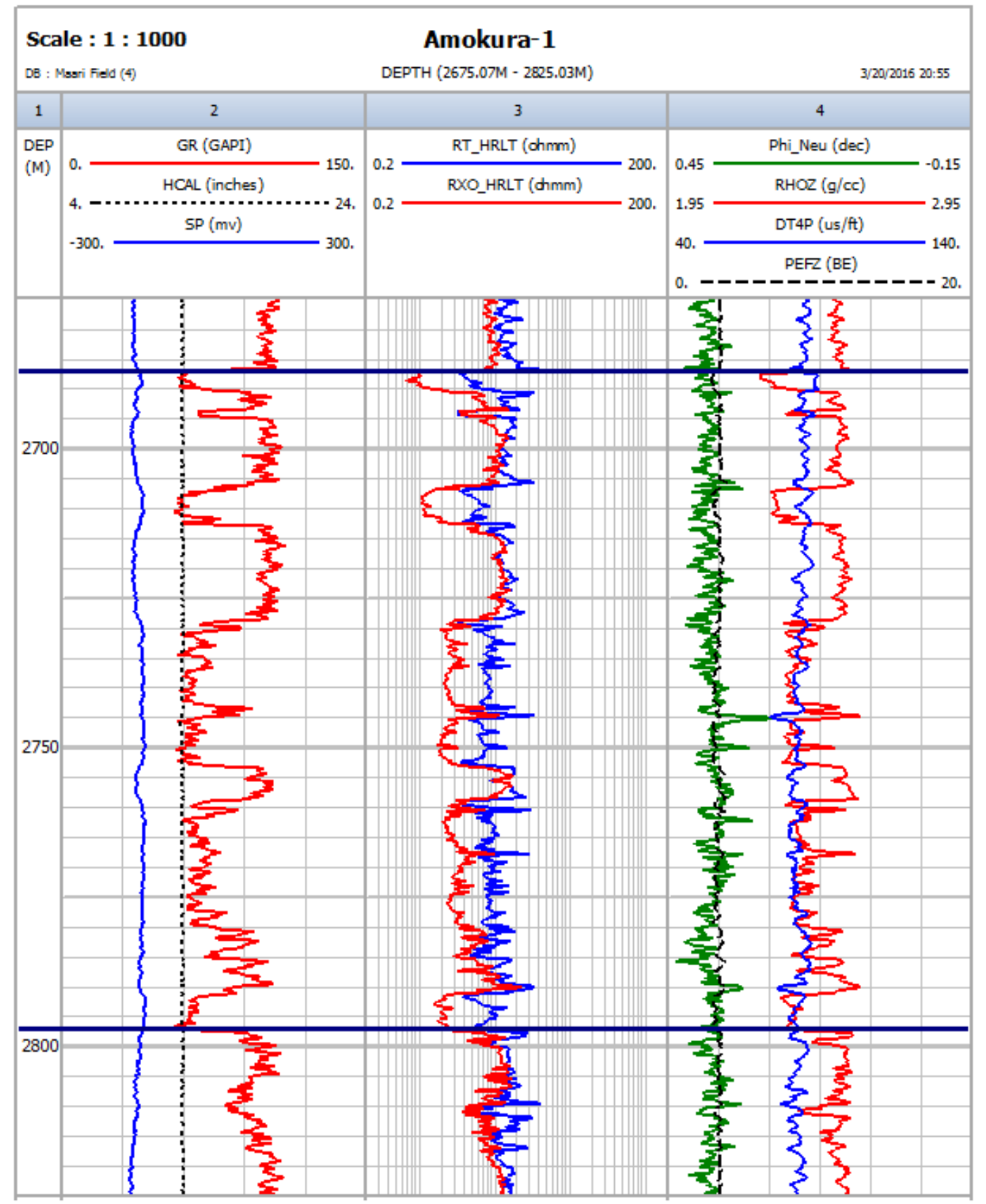

Figure 3.3. Litholog for Amokura-1 well. The first track shows depth range. The second track displays gamma ray (red), caliper (black), and spontaneous potential (blue) logs. The third track represents resistivity logs: deep lateralog (blue), shallow lateralog (red), and micro-resistivity log (green). The fourth track identifies neutron (green), density (red), sonic (blue), and photoelectric absorption (black) logs. 


\subsection{Petrophysical Analysis}

Conventional petrophysical analysis was applied to the selected wells to identify the mineral composition, porosity, and water saturation of Moki Formation. Shale fraction was calculated by using linear relationship between index of sand and shale volume from gamma ray $\log$ (Appendix (I)). Sand and shale values were estimated by visual inspection of the gamma ray log. In order to determine fractions of the other minerals, the gamma ray, density, neutron, and photoelectric absorption logs were used. Porosity was calculated using average of the neutron and density logs (Appendix (I)). Neutron porosity had been recorded on a limestone basis; therefore, it was converted on a sandstone basis in order to use in the calculations. Finally, the deep lateralog, shallow lateralog, neutron log, and density $\log$ were used to determine water saturation profile.

\subsubsection{Crossplot Analysis and Mineral Identification}

Crossplots provide a good visual description of lithology and help to determine some required parameters (e.g., GR values for sand and shale, and NPHI, RHOB, PEF values for shale). Three different crossplots were prepared for the selected wells: NPHI-RHOB, UMA (matrix volumetric factor)-DGA (dry grain density), and PEF-RHOB.

Typical NPHI-RHOB crossplot, with the color bar showing GR log, is shown in Figure 3.4.a-b. These crossplots indicate high concentration of shale in the formation. Because of the high content of shale, all points tend to move towards the shale point. Radioactive elements are more concentrated in shale as compared to other common rock types. Because gamma ray tools record the natural radioactivity of the formation, higher gamma ray 
readings are recorded in shale. Additionally, high neutron response is recorded in shale because of bound water in its structure.

Moki Formation is located at greater depths in the Tui Field than in the Maari Field. Due to this difference, it is expected that lower porosity readings should be recorded in the Tui Filed than in the Maari Filed. However, the Amokura-1 well, shown in Figure 3.4.b, exhibits higher neutron porosity values than the Moki-1 well, shown in Figure 3.4.a. This contrast can be explained by overpressure, or grain size distribution, or subsidence rate in the Tui Field.

In order to examine this contrast, we prepared a composite log that shows gamma ray, neutron, density, and sonic logs of these two wells together, shown in Figure 3.5. Compaction trends in the two wells are somewhat similar up to $1500 \mathrm{~m}$. After that depth, they start to diverge. The trends in both wells do not suggest overpressure in the depth ranges made consideration (see Figure 3.5), since the trends are generally consistent and do not reserve. Having higher porosity readings in deeper depths may be explained by well sorted grain size distribution in the Tui Field. The formation may have larger grain size distribution in the Maari Filed than in the Tui Filed. Furthermore, this contrast may be explained by subsidence rates. That is the deeper Moki formation in the Amokura-1 well seems to be less-compacted than in the Moki-1 well, even though it is $1100 \mathrm{~m}$ deeper. The shaliness of the Amokura-1 well, as indicated by the GR log, suggests that the bound water in the shales has not been released with subsidence, and remains in the formation. It is possible that the part of the basin containing the Amokura-1well subsided much more 
quickly than mean the Moki -1 well, retaining its higher porosity to greater depth, but an analysis of sedimentary and diagenetic history is beyond the scope of this study.
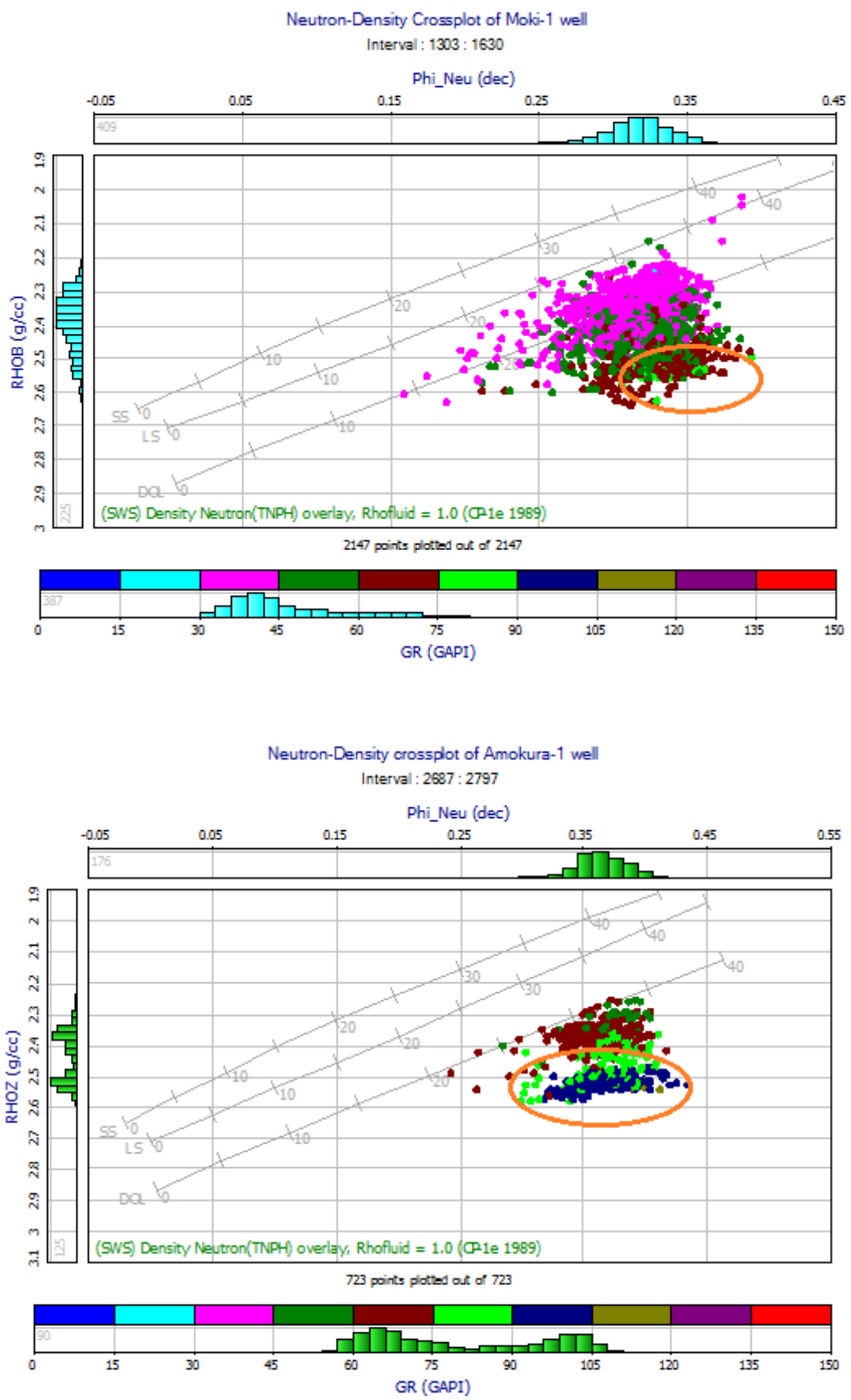

Figure 3.4. Neutron-Density Crossplots of Moki-1 well (a) and Amokura-1 well (b) indicate that the Moki Formation consists of considerable amount of shale. The color bar shows the gamma ray log. Each data point refers to different depth in the Moki Formation. The orange circles in crossplots indicate "pure" shale point locations. 


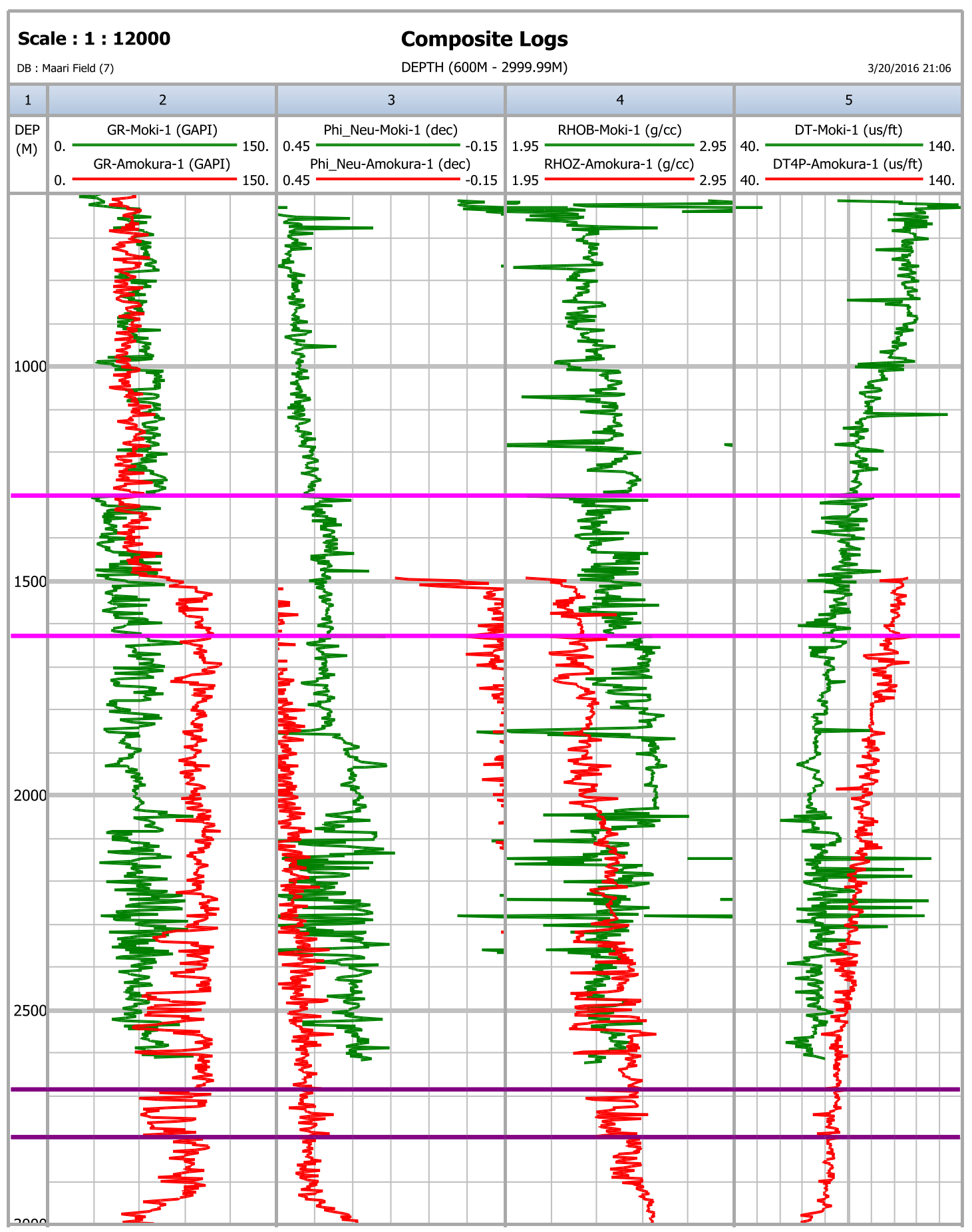

Figure 3.5. Composite litholog of Moki-1 well (green) and Amokura-1 well (red). The first track shows depth range. The second, third, fourth, and fifth tracks display gamma ray, neutron porosity, density, and sonic logs, respectively. 
For accurate determination of mineral composition, UMA-DGA (obtained by using NPHI, RHOB, and PEF logs, Appendix I), shown in Figure 3.6.a-b, and PEF-RHOB, shown in Figure 3.7.a-b, crossplots have also been prepared. These crossplots indicate that Moki Formation does not consist of pure sandstone. Because of the considerable amount of shale, the points on the crossplots tend to locate between sandstone and shale points.

The points in Figure 3.6.a and Figure 3.7.a (for the shallower Maari Filed) are closer to sandstone point than in Figure 3.6.b and Figure 3.7.b (for the deeper Tui Field). Due to the higher PEF and UMA values in the Tui Field, we may conclude that these two fields have different types of clay. While the points in the Maari Field tend to move towards illite, the points in the Tui Field tend to move towards chlorite; this may help explain the different compaction trends. These crossplots also indicate the presence of small amount of limestone in the formation. 

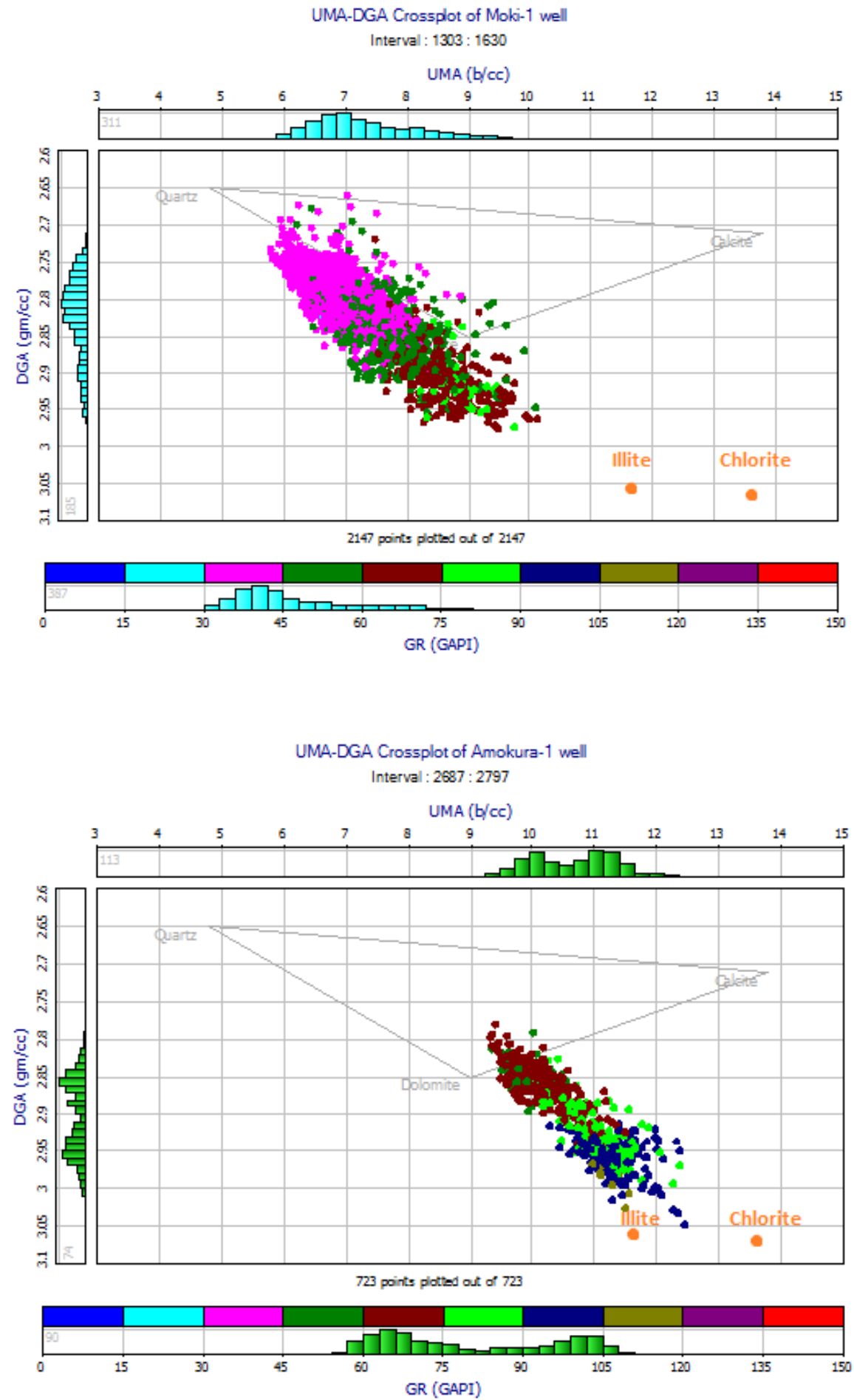

Figure 3.6. UMA-DGA Crossplots of Moki-1 well (a) and Amokura-1 well (b) indicate that the points in the crossplots are located between sand and shale points due to the high content of shale. In addition, these crossplots indicate that the Moki Formation comprises of small amount of limestone. The color bar shows the gamma ray log. 

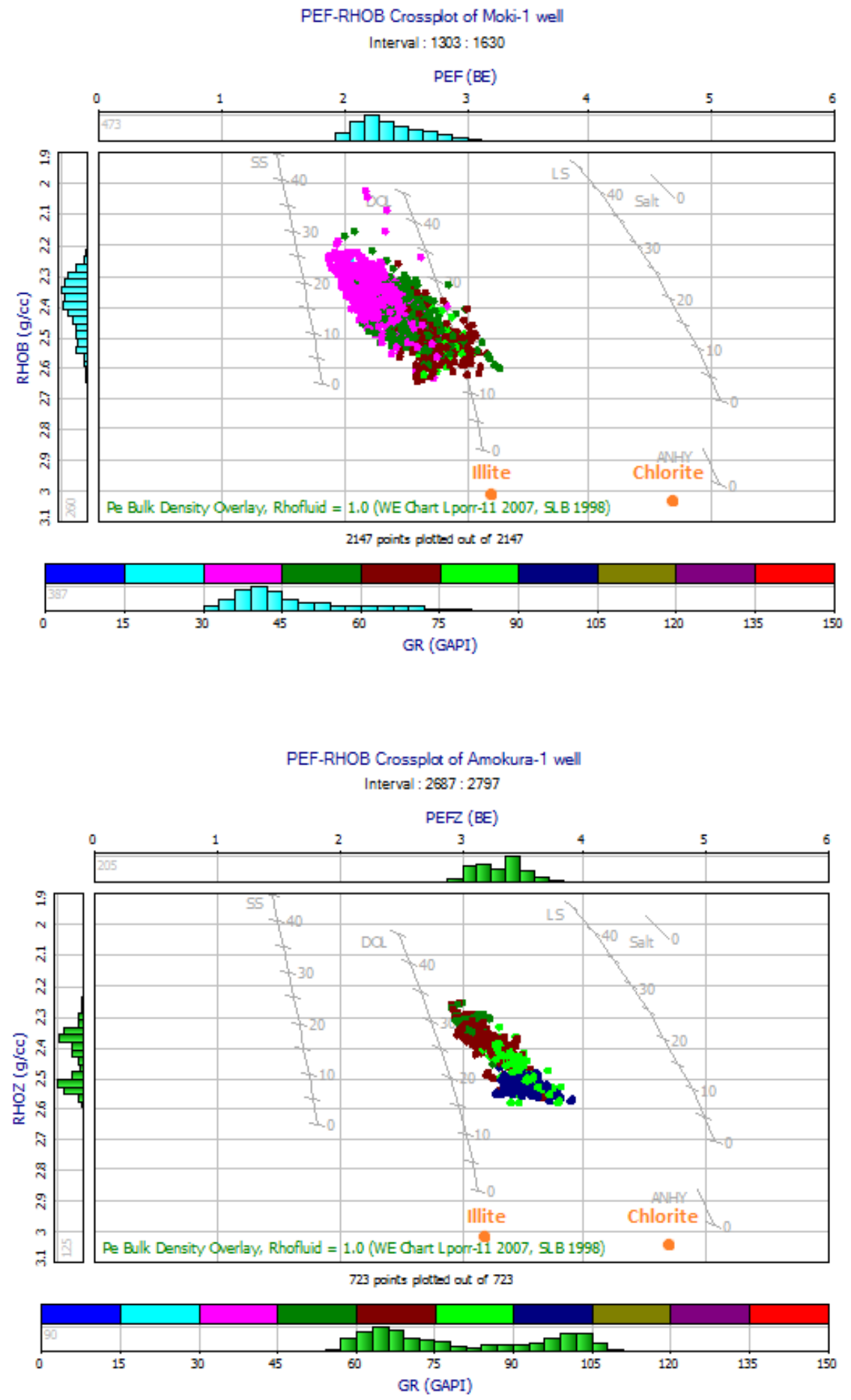

Figure 3.7. PEF-RHOB Crossplots of Moki-1 well (a) and Amokura-1 well (b) indicate that each well comprises of different types of clay. The color bar shows the gamma ray log. 
According to these three crossplots, both the Maari Field and the Tui Field present the same kind of trend and show that the Moki Formation consists of sandstone and shale with a small amount of limestone. Moreover, there are some distinctions in crossplots because of the depth, distance, and variations of clay types in these two wells.

After determining mineral composition by using crossplots, a conventional 3-mineral identification approach was applied to calculate the fractions of these three minerals. The gamma ray, density, neutron, and photoelectric absorption logs were used, as explained in Appendix II with all the parameters and equations. The results for reference wells are shown in Figure 3.9-10, along with the saturation results obtained in the following section.

\subsubsection{Saturation}

The dual-water model was used to calculate water saturation profile by using the deep lateralog, shallow lateralog, neutron, and density logs. The model is explained in Appendix III, along with the parameters and equations. Formation water resistivity $\left(\mathrm{R}_{\mathrm{w}}\right)$, cementation factor $(\mathrm{m})$, and saturation exponent (n) are some of these required parameters for computing the model. These Archie parameters were obtained from Pickett plot.

For Moki-1 well, 1327m was chosen as water-oil contact as suggested by the character of the resistivity curves. To determine the Archie parameters, Pickett plot shown in Figure 3.8.a was prepared from the top of the formation at $1303 \mathrm{~m}$ depth, through the water-oil contact, to $1335 \mathrm{~m}$ depth, well into the water zone. 
For Amokura-1 well, there is no distinctive depth to determine water-oil contact in resistivity curves. Because of the absence of water-oil contact, all depths in Moki Formation were used to prepare Pickett plot shown in Figure 3.8.b.

The cementation factor is ranging from 1.8 to 2 for consolidated sandstone (Archie (1942)). Because of the high cementation in the studied wells, we took higher cementation factor value than 2. The factor is related to the slope of the curve in the Pickett plot. When we examine the Pickett plots, there is a small change in the oil saturation curves even if the cementation factor is taken higher than 2 .

After applying dual-water model, saturation profiles were obtained and results were shown in Figure 3.9 for Moki-1 well and in Figure 3.10 for Amokura-1 well. 


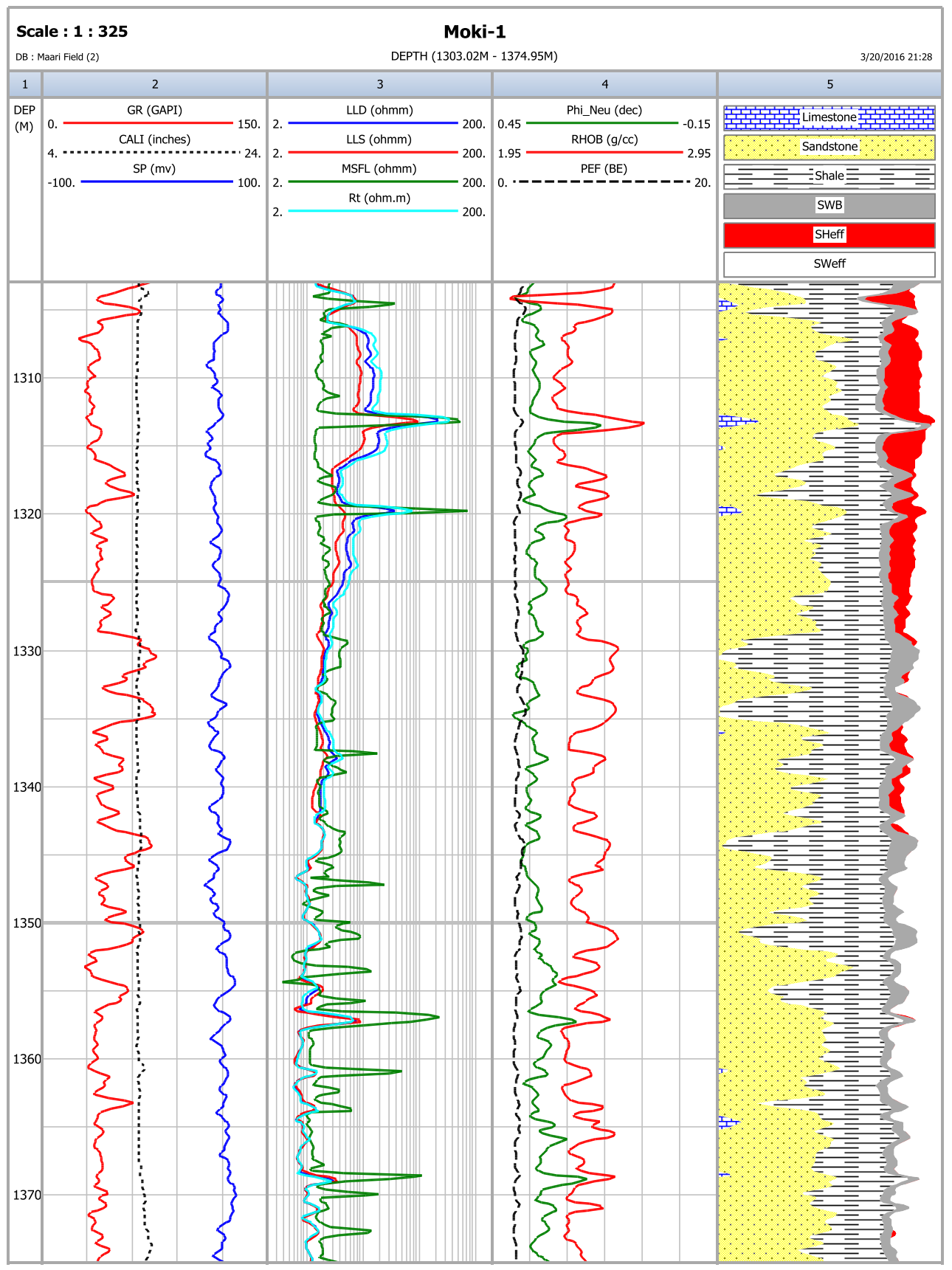

Figure 3.9. Litholog for Moki-1 well. The first track shows depth range. The second track displays gamma ray (red), caliper (black), and spontaneous potential (blue) logs. The third track represents resistivity logs: deep lateralog (blue), shallow lateralog (red), microspherically focused (green), and true resistivity (light blue) derived from formula. The fourth track identifies neutron (green), density (red), and photoelectric absorption (black) logs. The last track shows the lithology obtained from a 3-mineral identification approach and dual-water model. In order to provide high resolution, just 75 meters of the formation was shown in here. The entire formation was plotted in the Appendix (IX). 


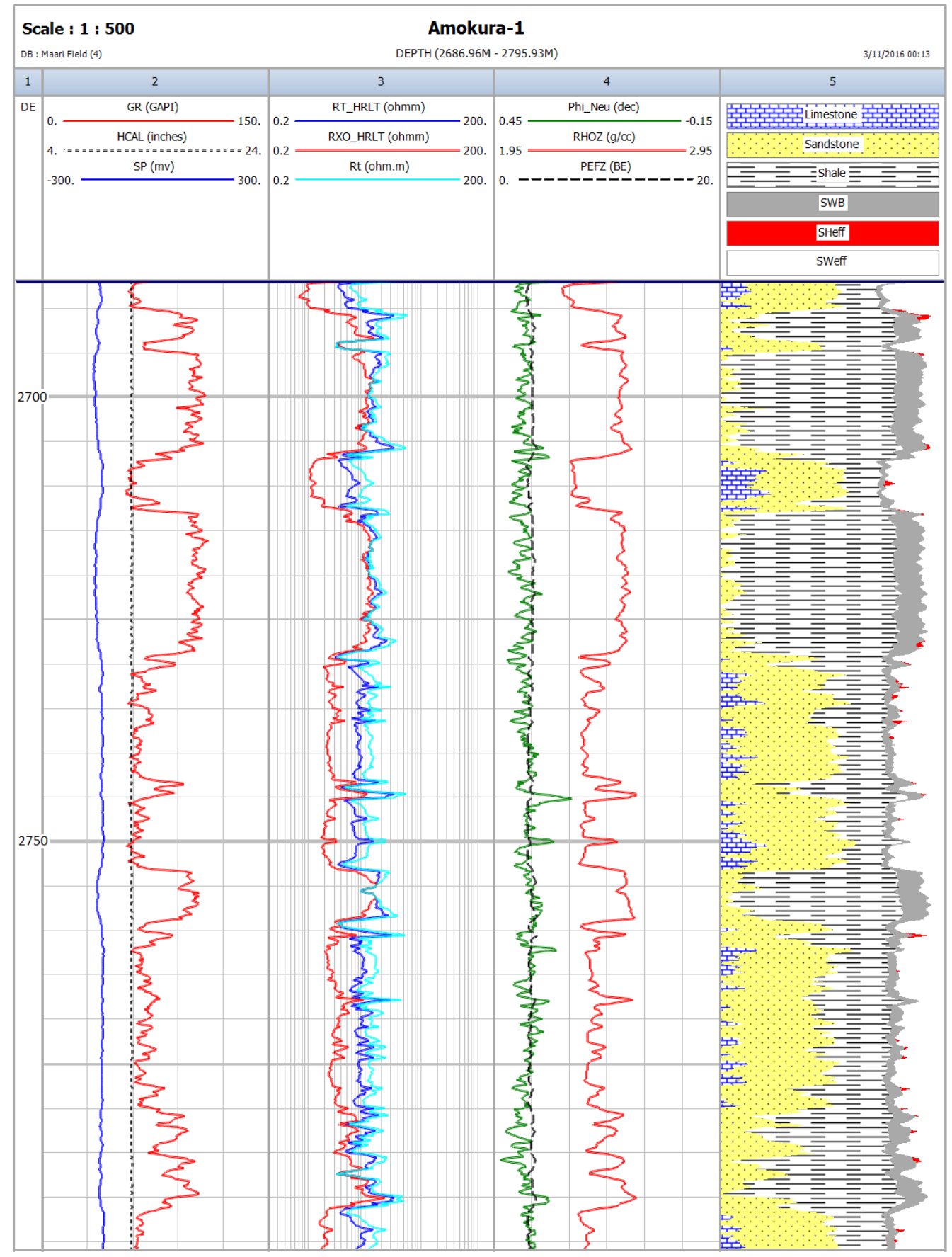

Figure 3.10 Litholog for Amokura-1 well. The first track shows depth range. The second track displays gamma ray (red), caliper (black), and spontaneous potential (blue) logs. The third track represents resistivity logs: deep lateralog (blue), shallow lateralog (red), and true resistivity (light blue) from formula. The fourth track identifies neutron (green), density (red), and photoelectric absorption (black) logs. The last track specifies the lithology found by applying 3-mineral identification approach and dual-water model. 


\subsection{Sonic Response Prediction}

In this section, empirical relationships and rock physics model approaches were applied to the selected wells to predict sonic response: Wyllie's Time Average equation, Greenberg and Castagna's relation, and Kuster - Toksoz rock physics model. The lithology, porosity, and the fluid content in pores are required parameters for applying these approaches. Lithology determination was described in the previous section, and the average of the density and neutron porosities was used for the porosity estimation. These approaches were applied by assuming water-saturated matrix. Finally, the results were compared with observed sonic response.

\subsubsection{Empirical Relations}

First, Wyllie's Time-Average equation, which is one of the empirical relations (Wyllie et al., 1956), is used to estimate the compressional transit time by using the information of lithology, porosity, and fluid content in pores (Appendix (IV)) and is compared with the recorded DT values. Table 3.1 shows the travel times of each mineral used in the calculations. The $5^{\text {th }}$ tracks in Figure 3.15-16 (presented following the Kuster-Toksoz discussion) show the P-wave velocity results obtained from Wyllie's Time Average equation.

Table 3.1 The matrix travel times of each mineral used in the calculations.

\begin{tabular}{|l|l|l|l|l|l|}
\hline Mineral Types & Quartz & Calcite & Illite & Chlorite & Water \\
\hline $\begin{array}{l}\text { Travel Time } \\
\text { (Slowness) } \\
\text { (usec/ft) }\end{array}$ & 56 & 47 & 64 & 55.5 & 189 \\
\hline
\end{tabular}


The second empirical relation is used to predict shear wave velocity: Greenberg and Castagna's relation (Greenberg and Castagna, 1992). This is the relationship between compressional and shear wave velocities depending on the lithology (Appendix (IV)). Predicted sonic response was compared only with the rock physics model result, which will be discussed in the following section, because none of our wells has recorded shear sonic response. The $6^{\text {th }}$ tracks in figure 3.15-16 show the S-wave velocity results obtained from Greenberg and Castagna's relation.

\subsubsection{Rock Physics Model}

To predict compressional and shear-wave velocities in clay-sand mixture, several theoretical models have been developed. One of them is Xu and White (1995) model which is based on the Gassmann (1951, 1965) model and Kuster-Toksoz model (1974). The model divides pore space into two parts. One of them is associated with sand and the other one is associated with clay. These parts have different pore aspect ratio, which is a ratio of short axis to long axis. The $\mathrm{Xu}$ and White model associates the effect of clay content and these pore aspect ratios with the sonic velocities.

In this study, the $\mathrm{Xu}$ and White model was applied to selected wells to predict sonic velocities and compare them with observed P-wave velocity derived from DT log and the predicted P-wave and S-wave velocities obtained from empirical relations. The model was explained in Appendix VI with the parameters and equations. Instead of using dry-rock frame properties, water-saturated rock properties were simply employed for calculations in here; therefore, the Gassmann model aspect of the Xu and White model was not performed. 
The optimal aspect ratios for sand and for clay were chosen on a RMS (Root Mean Square) error basis, shown in Appendix V, by using a range of pore aspect ratios and finding the minimum RMS error (agreement with observed P-wave velocity). We prepared a contour map to pick the minimum RMS value that gives the best sonic prediction fit with the observed P-wave velocity. Figure 3.11.a-b show the contour map for the reference wells, respectively for Moki-1 well and Amokura-1 well. Both wells exhibit the same sort of trend. According to Figure 3.11.a-b, the lower RMS errors can be found using the aspect ratios between 0.15 and 0.2 for sand-related pores and between 0.10 and 0.15 for clayrelated pores, but the values are poorly constrained due in large part to the limited range of porosities in the formation. 

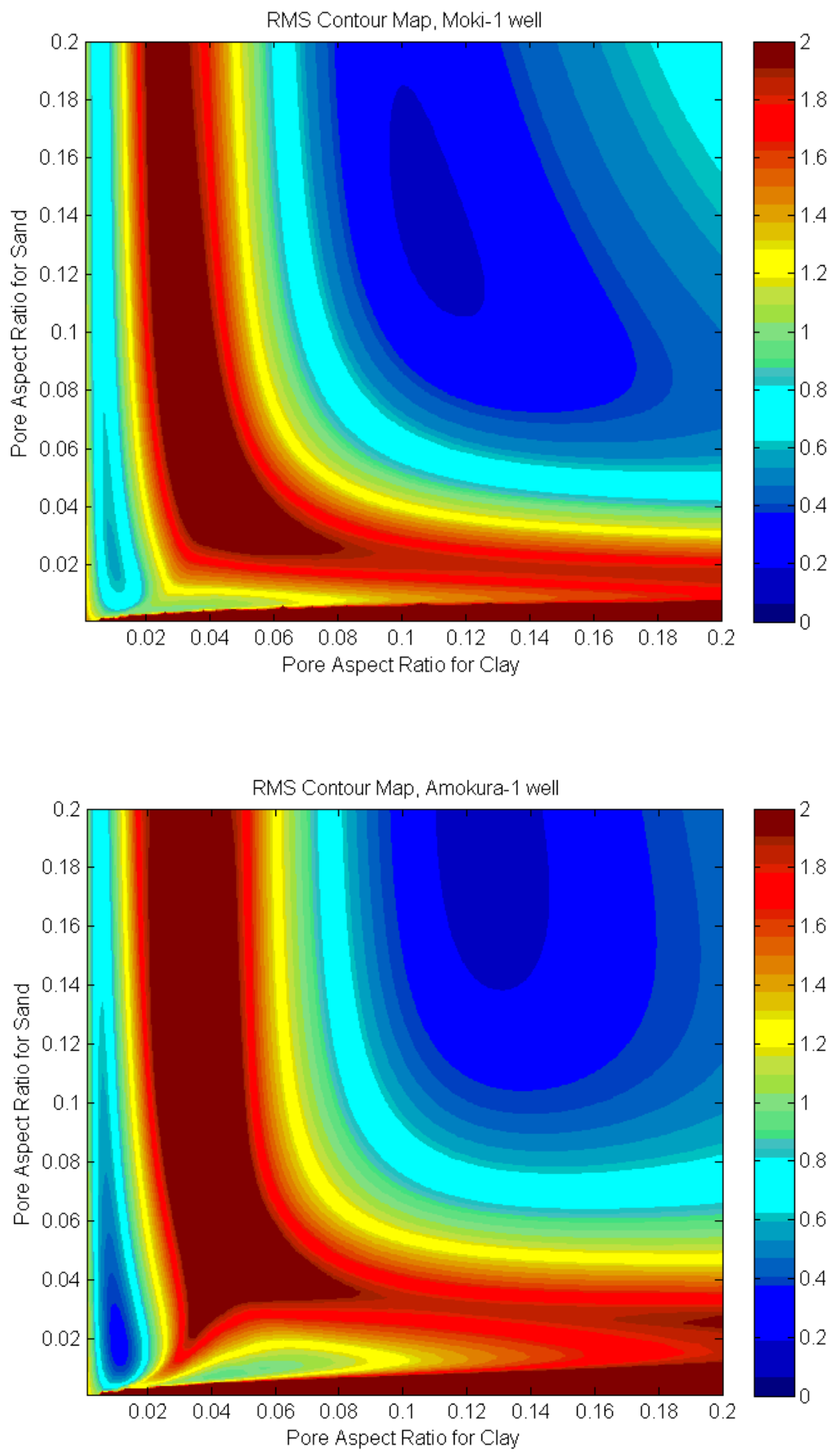

Figure 3.11. RMS contour maps of Moki-1 well (a) and Amokura-1 well (b) help to identify the aspect ratios for sand and clay and those which give the minimum RMS error. 
In Figure 3.15-16, the first tracks show depth range. The second tracks display the gamma ray, caliper, and spontaneous potential logs. The third tracks identify resistivity logs: deep lateralog, shallow lateralog, micro-spherically focused, and true resistivity obtained from the formula. The fourth tracks represent neutron, density, and photoelectric absorption logs. The compressional wave velocities that are observed from sonic log and predicted from Wyllie's Time Average equation and Kuster-Toksoz model are shown in the fifth tracks. The shear wave velocities predicted from Greenberg-Castagna equation and KusterToksoz model are presented in the sixth tracks. The last tracks in these figures display the lithology log which was attained from 3-mineral identification approach and dual-water model.

In order to determine differences between the predicted P-wave velocities, we prepared crossplots between observed P-wave velocity derived from sonic log and predicted P-wave velocity from Wyllie's Time Average equation and Kuster-Toksoz model for each well, shown in Figure 3.12-13. According to Figure 3.12.a-b, Kuster-Toksoz model works better in shale than Wyllie's Time Average equation. Due to the bound water in shale structure, higher density response is recorded in shale. This situation causes to predict higher P-wave velocities calculated from Wyllie's Time Average equation in shale. For the Amokura-1 well, Figure 3.13.a implies that Wyllie's Time Average equation works better in shale than in sandstone. Because of the less compaction or/and well-sorted grain size distribution in deeper depths, higher porosity response are recorded; therefore, predicted P-wave velocities from Wyllie's Time Average equation are lower than P-wave velocities derived from sonic log. In Kuster-Toksoz model, we optimize parameters in order to obtain best fit 
with the observed P-wave velocity derived from sonic log and Figure 3.12.b and Figure 3.13.b show how well they fit for each well.

While we do not have an S-wave log for comparison, we note that the Greenberg-Castagna model consistently predicts a lower S-wave velocity than the Kuster-Toksoz model, expect in the highest-velocity streaks where limestone is likely present. We may conclude that by taking saturation profile of Moki-1 well into consideration, shown in Figure 3.9, because we employed water-saturated rock properties for Kuster-Toksoz model, the model predicts higher S-wave velocity than the Greenberg-Castagna model. For Amokura-1 well, there are no significant differences between the results from empirical relations and rock physics model. Both predictions gave similar results for this well. But this comparison is not reliable, because we do not have any S-wave log. 

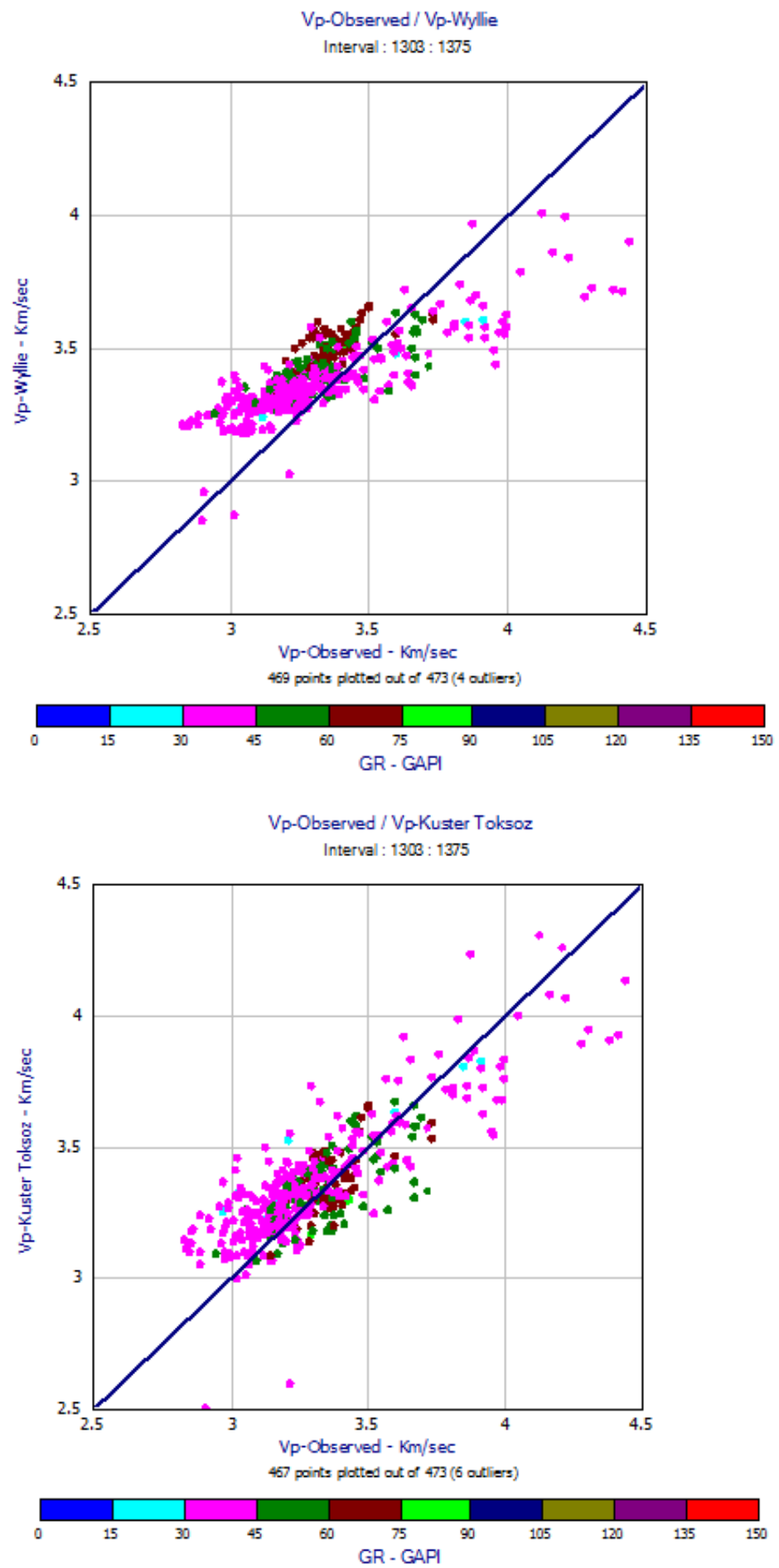

Figure 3.12. The crossplot of observed P-wave velocity derived from sonic log and predicted P-wave velocity from Wyllie's Time Average equation (a) and Kuster-Toksoz model (b) of Moki-1 well. The color bar shows the gamma ray log. 

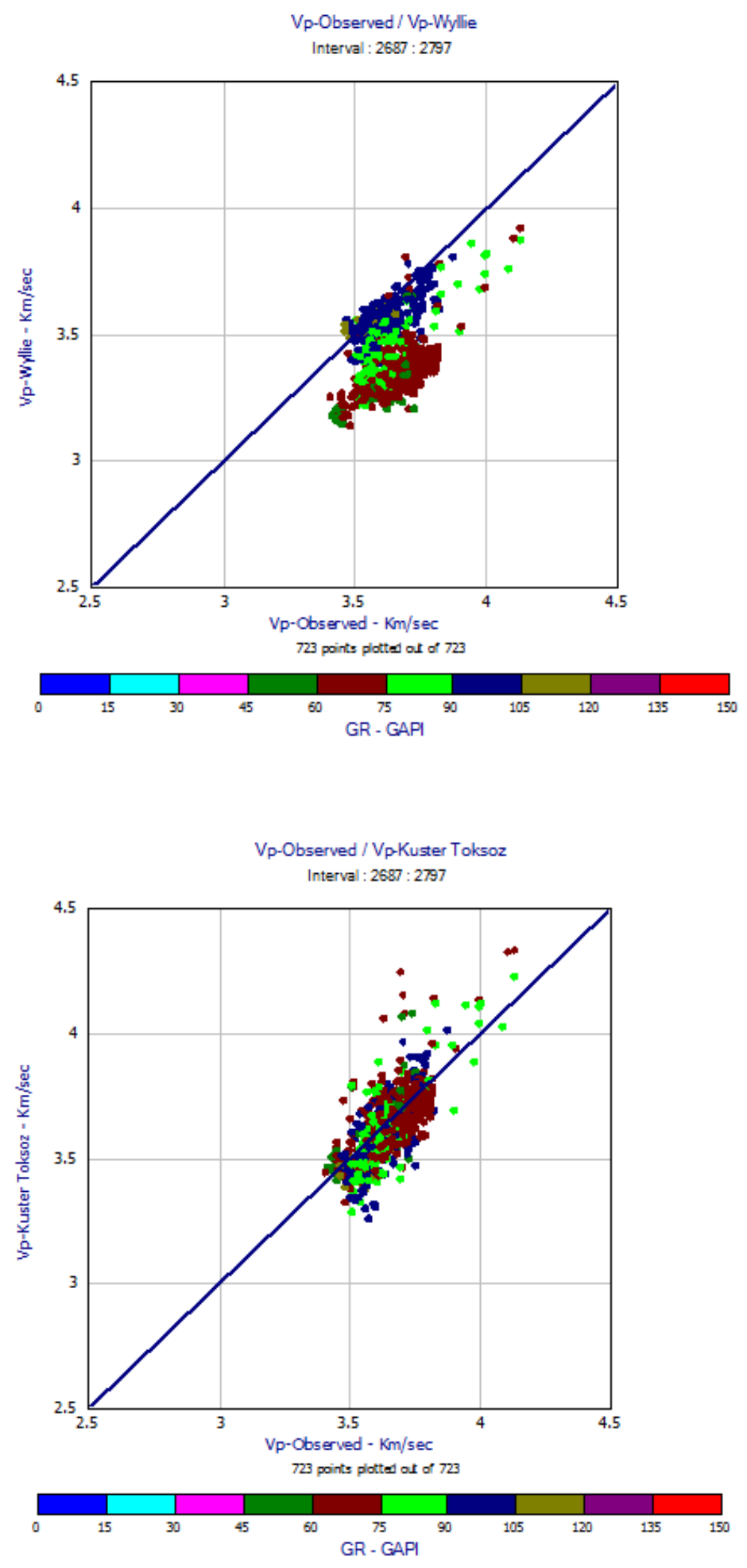

Figure 3.13. The crossplot of observed P-wave velocity derived from sonic log and predicted P-wave velocity from Wyllie's Time Average equation (a) and Kuster-Toksoz model (b) of Amokura-1 well. The color bar shows the gamma ray log. 

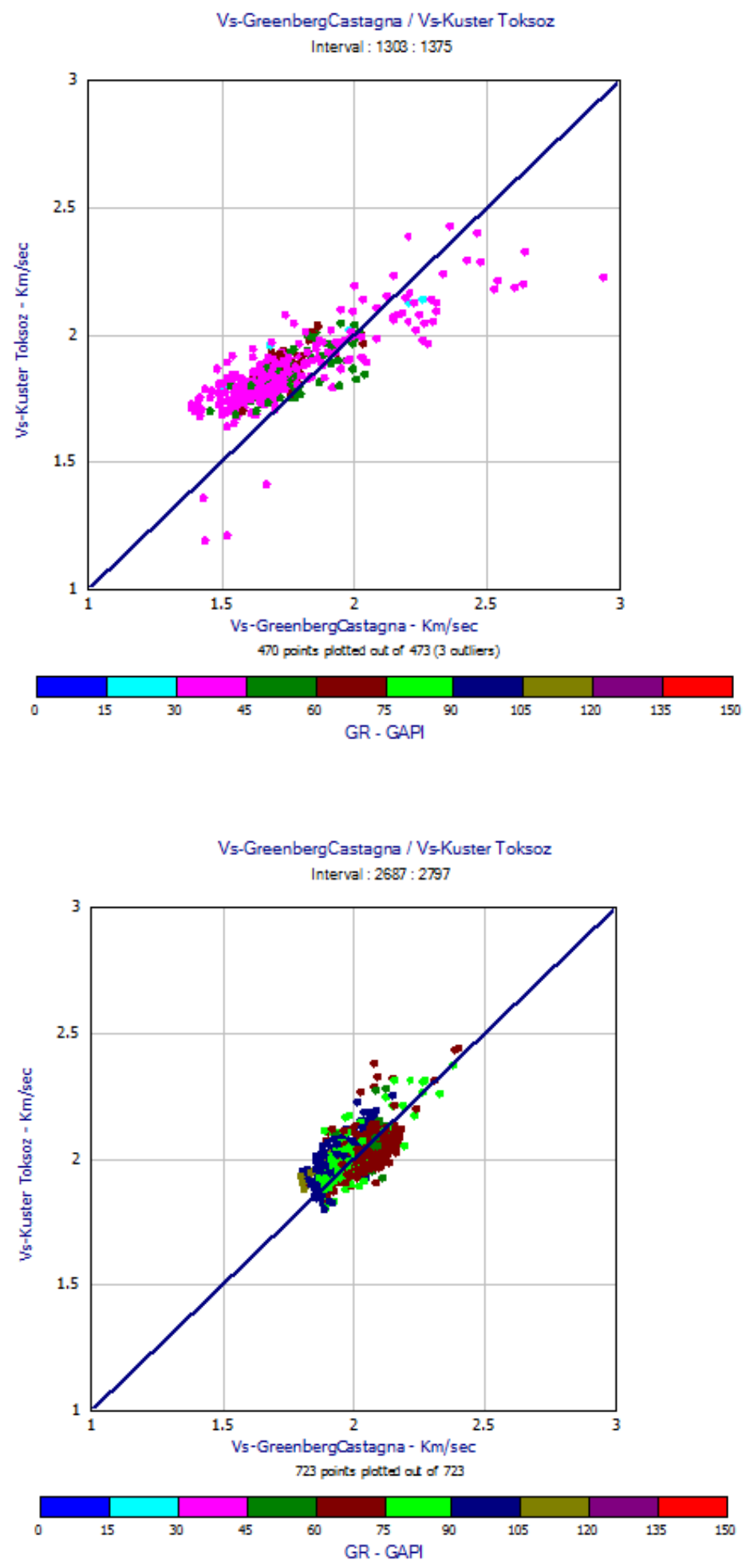

Figure 3.14. The crossplot of predicted S-wave velocity derived from Greenberg-Castagna relation and predicted S-wave velocity from Kuster-Toksoz model for Moki-1 well (a) and Amokura-1 well (b). The color bar shows the gamma ray log. 


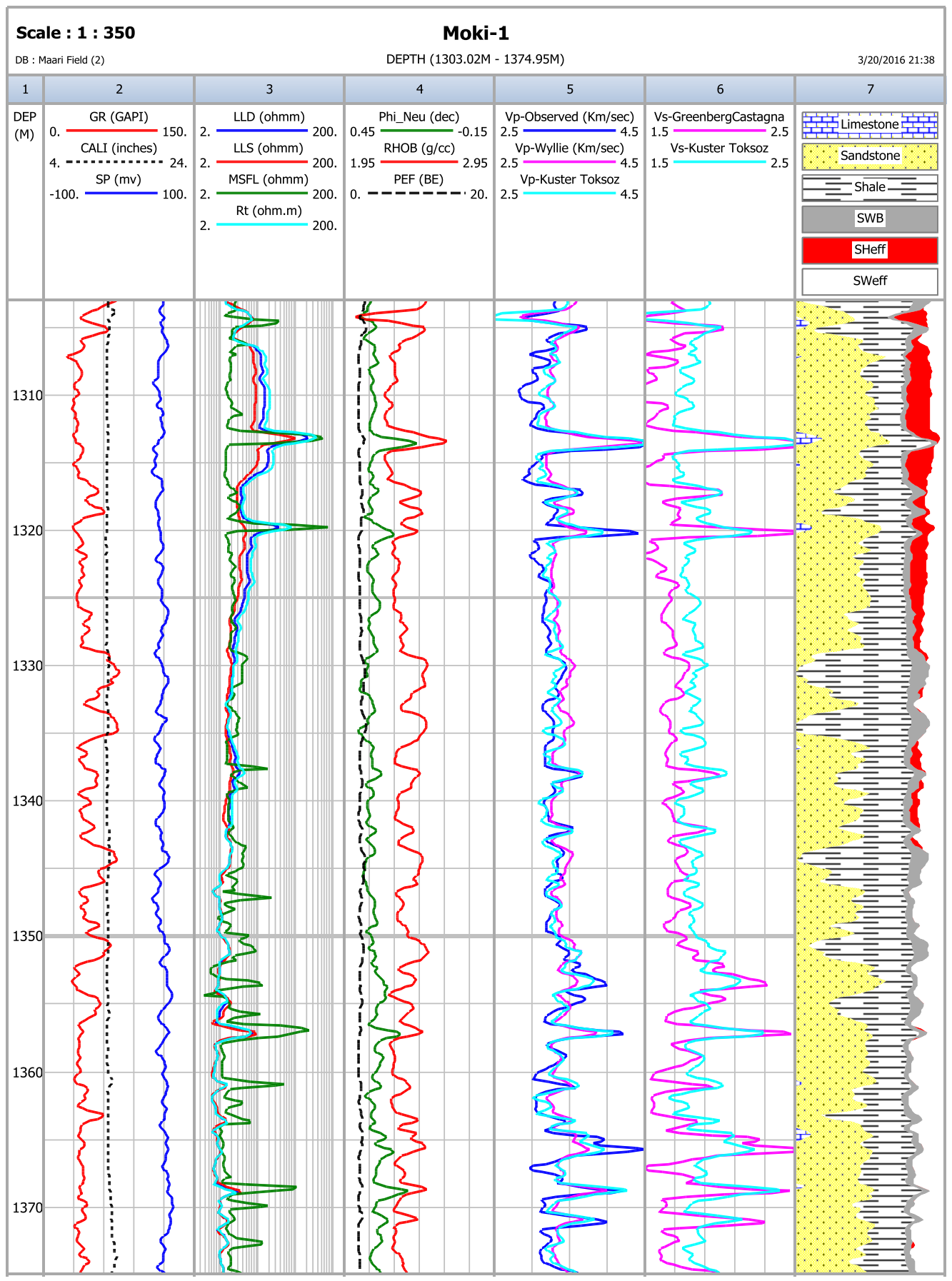

Figure 3.15. Sonic wave prediction logs for Moki-1 well. The fifth track shows the P-wave velocities: observed from sonic log (blue), predicted from Wyllie' Time Average Equation (pink) and Kuster-Toksoz model (light blue). The sixth track displays the S-wave velocities: predicted from Greenberg-Castagna relation (pink) and Kuster-Toksoz model (light blue). Moki formation is located between 1303 and 1630 meters in Moki-1 well. For displaying with high resolution, just 75 meters of Moki Formation is shown in here. Whole formation is plotted in the Appendix (IX). 


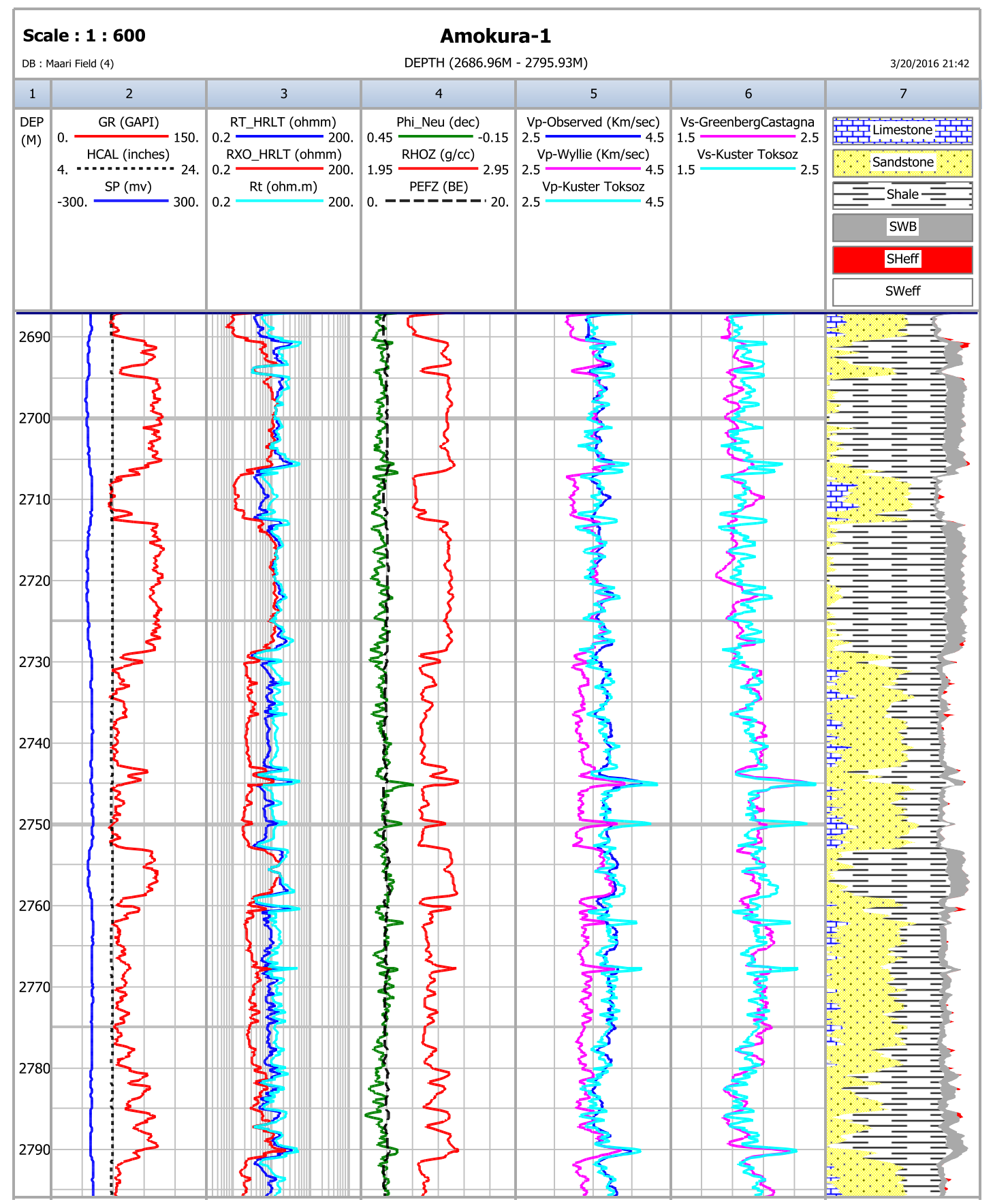

Figure 3.16. Sonic wave prediction logs for Amokura-1 well. The fifth track shows the Pwave velocities: observed from sonic log (blue), predicted from Wyllie' Time Average Equation (pink) and Kuster-Toksoz model (light blue). The sixth track displays the S-wave velocities: predicted from Greenberg-Castagna relation (pink) and Kuster-Toksoz model (light blue). Moki formation is located between 2687 and 2797 meters in Amokura-1 well. 


\subsection{Fluid Substitution for Velocity Predictions}

One of important benefits of petrophysical analysis is fluid substitution analysis for seismic velocities, used for the interpretation of both logging and seismic data. It is also a useful tool for the fluid identification and quantitative reservoir research. Gassmann's (1951) equation is the most common method for applying fluid substitution in porous rocks. The equation is used here to predict sonic velocities of rocks saturated with one pore fluid with another fluid by using the properties of the rocks as measured by logs.

The substitution supposes that the pore fluid attains instantaneous hydraulic equilibrium throughout the pore space. However, this supposition is not applicable for shaley sediment because impermeable shale structure contains bound water (Dvorkin et al., 2007). In order to apply Gassmann's equation in shaley sediment, the equation can be modified by taking effective porosity into account.

In this section, for shaley sediment, two different alternative fluid substitution methods were applied to the selected wells to predict sonic velocities and compare the methods with each other. In this study, since there are no recorded S-wave logs, we used an approximate $\mathrm{V}_{\mathrm{p}}$-only fluid substitution method, from Mavko et al. (1995), that uses the compressional modulus; the equations shown in Appendix VII for the shaley-sand methods described in the following sections reflect this modification. For the calculations, the water saturation profile which was computed by applying the dual-water model, explained in Chapter 3.1.2, was used. To perform the substitution, we replaced the oil with gas for the first exercise and then with water in the second exercise. 


\subsubsection{Fluid Substitution in Shaley Sediment using Effective Porosity}

Dvorkin et al. (2007) developed an alternative fluid substitution method for shaley sand by modifying Gassmann's equation. The method introduces porous wet shale as a new mineral phase in the matrix. According to this method, composite mineral phase consists of porous wet shale and nonporous minerals. Therefore, elastic modulus are calculated by taking this new mineral phase, porous wet shale, into account. Furthermore, in the calculations, effective porosity was used instead of total porosity. The method was explained in Appendix VII with all parameters and equations. Table 3.2 shows the modulus and density values of each component used in the calculations. Porous wet shale parameters were estimated by visual inspection of the logs.

Table 3.2 Modulus and density values of the components.

\begin{tabular}{|c|c|c|c|}
\hline Mineral Types & Bulk Moduli (GPa) & Shear Moduli (GPa) & Density $\left(\mathrm{g} / \mathrm{cm}^{3}\right)$ \\
\hline Quartz & 39 & 33 & 2.65 \\
\hline Shale & 25 & 9 & 2.55 \\
\hline Porous wet shale & 17 & 6.8 & 2.4 \\
\hline Water & 2.2 & 0 & 1 \\
\hline Hydrocarbon & 1.22 & 0 & 0.75 \\
\hline Gas & 0.01 & 0 & 0.1 \\
\hline
\end{tabular}

Figure 3.17 shows the effects of shale volume, effective porosity, and effective water saturation on substituted sonic velocities and densities for two wells by applying Dvorkin et al' s approach. In Amokura-1 well, since the oil saturation is not enough to observe the differences between measured and substituted sonic velocities clearly, the range of 2760 2780 meters is modeled under the assumption that the original log was made under $50 \%$ oil saturation, and the fluid substitution is applied to this depth range, for demonstration purposes only. 


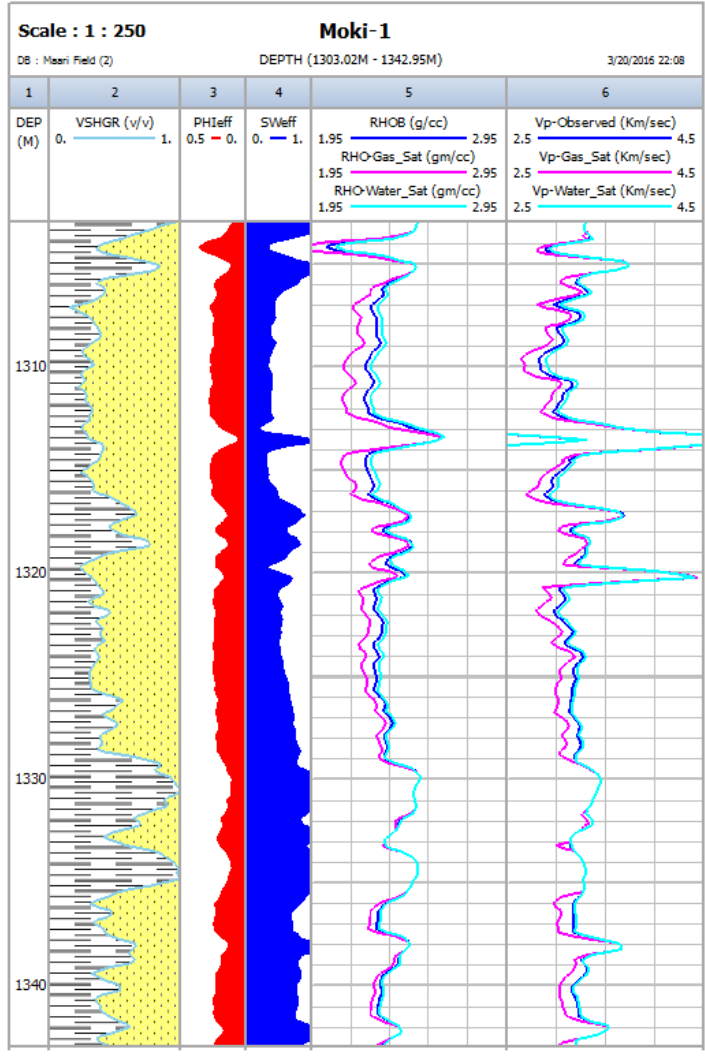

(a)

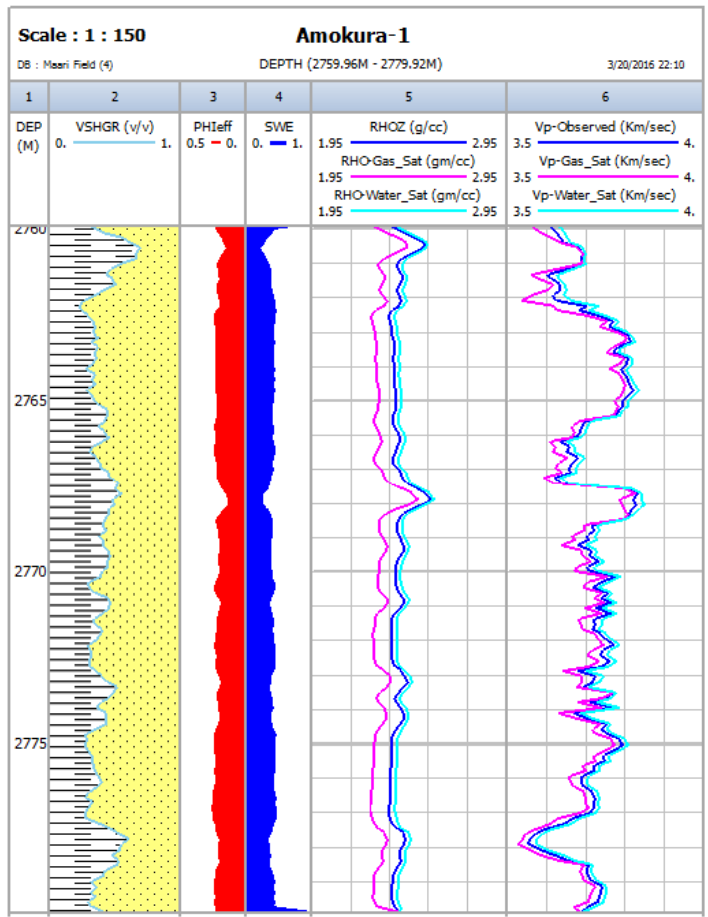

(b)

Figure 3.17. Substitution logs obtained from Dvorkin et al.'s approach for Moki-1 well (a) and Amokura-1 well (b). The first tracks show the depth range. The second, third and fourth tracks display respectively shale volume, effective porosity, and effective water saturation profile. The densities are shown in fifth tracks: observed (blue) and substituted assuming gas (pink) and water (light blue) instead of oil. The sixth tracks display sonic velocities: observed (blue) and substituted assuming gas (pink) and water (light blue) instead of oil.

As expected, when oil is replaced with gas, substituted P-wave velocity and density decreased. On the other hand, when oil is replaced with water, substituted P-wave velocity and density increased. 


\subsubsection{Practical Gassmann Fluid Substitution in Sand/Shale Sequences}

The other fluid substitution method examined here for shaley sediment is developed by Simm (2007). According to his model, there are two important aspects of fluid substitution on velocity determination: the role of pore space stiffness and the effect of gas saturation.

The pore space stiffness is associated with porosity, elastic modulus of the minerals, and modulus of dry frame. This relationship is shown in the following equation:

$$
K_{P H I}=\frac{\phi}{\frac{1}{K_{d}}-\frac{1}{K_{0}}}
$$

where $K_{P H I}$ is the pore space stiffness, $K_{d}$ is the dry rock bulk modulus, $K_{0}$ is the mineral modulus, and $\phi$ is the porosity. By taking the pore space stiffness into account, Gassmann's equation is modified by removing dry frame from the equation.

Although the paper includes both effective and total porosity approaches, in here, we just used the effective porosity approach. The method was explained in Appendix VII with all parameters and equations. Table 3.2 shows the modulus and density values of each component used in the calculations.

The results of this approach for two wells were presented in Figure 3.18 by displaying the effects of shale volume, effective porosity, and effective water saturation on substituted sonic velocities and densities. In Amokura-1 well, since the oil saturation is not enough to observe the differences between measured and substituted sonic velocities clearly, the range of $2760-2780$ meters is assumed $50 \%$ oil saturated and the fluid substitution is applied to this depth range, for demonstration purposes. 


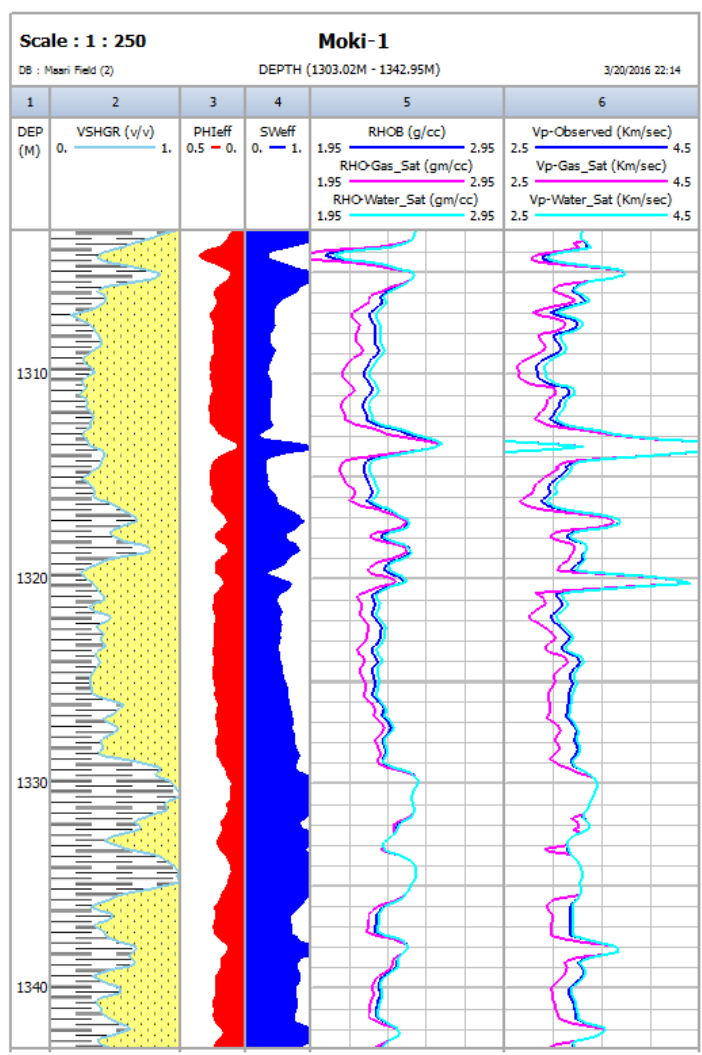

(a)

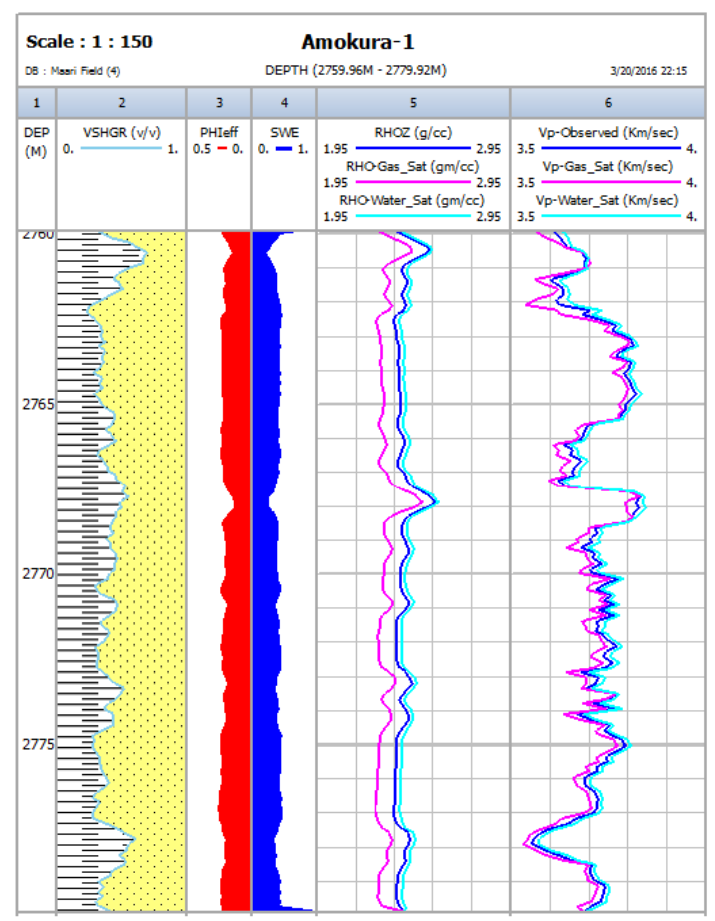

(b)

Figure 3.18. Substitution logs obtained from Simm's approach for Moki-1 well (a) and Amokura-1 well (b). The first tracks show the depth range. The second, third and fourth tracks display respectively shale volume, effective porosity, and effective water saturation profile. The densities are shown in fifth tracks: observed (blue) and substituted assuming gas (pink) and water (light blue) instead of oil. The sixth tracks display sonic velocities: observed (blue) and substituted assuming gas (pink) and water (light blue) instead of oil.

This approach also produced expected results. The P-wave velocity and density decreased upon replacing oil with gas and they increased with water. 


\subsubsection{Comparison of the Approaches}

According to Figure 3.17-18, there are no significant differences between the results obtained from Dvorkin et al.'s approach (first) and from Simm's approach (second). Both substitutions gave similar and expected results for both field. In order to compare these two approaches, the crossplots of the substituted P-wave velocities derived from Dvorkin et al.'s approach against from Simm's approach were prepared for replacing oil with gas for each reference well. The crossplots are shown in Figure 3.19-20, respectively for Moki-1 well and Amokura-1 well.

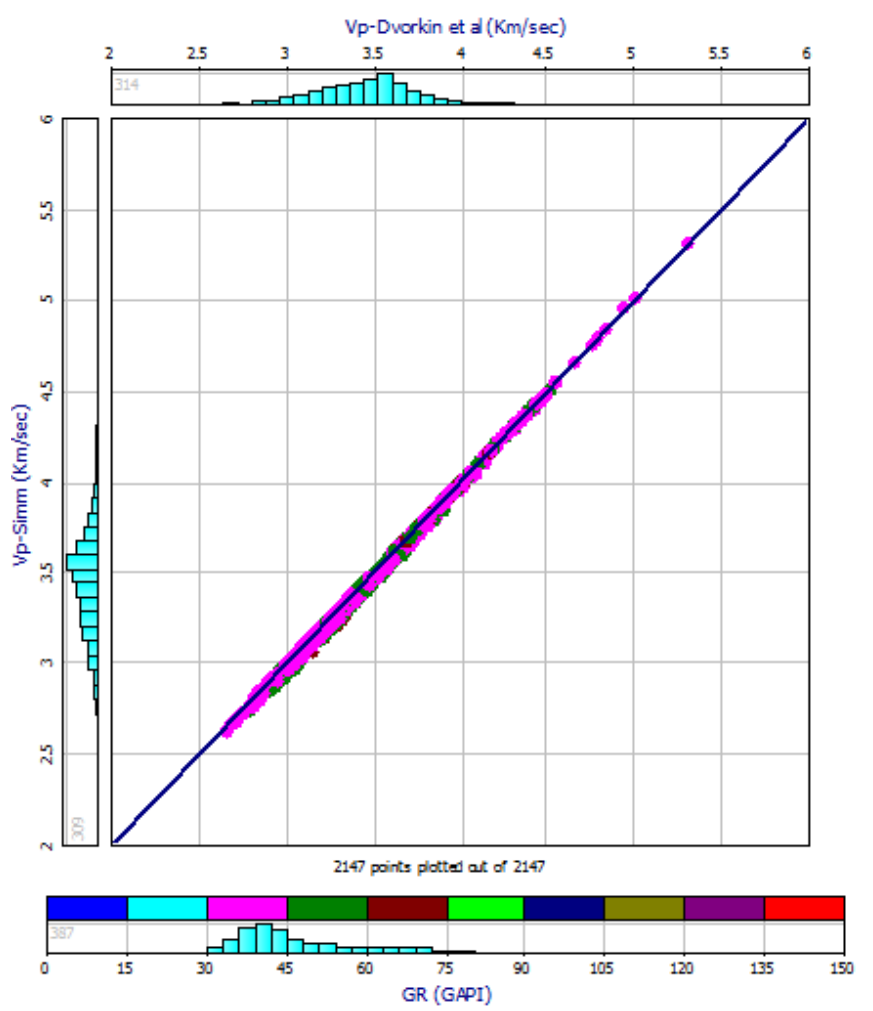

Figure 3.19. The crossplot of the substituted P-wave velocities derived from Dvorkin et al.'s approach against from Simm's approach of Moki-1 well. The color bar shows the gamma ray log. 


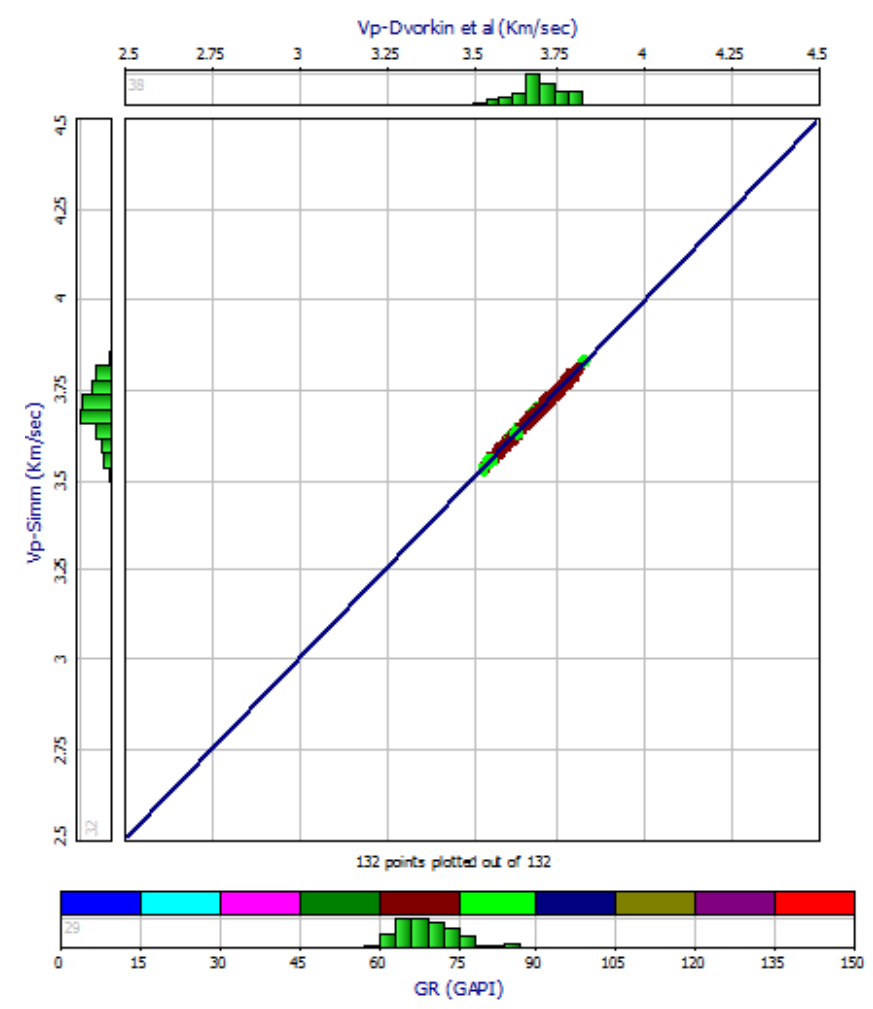

Figure 3.20. The crossplot of the substituted P-wave velocities derived from Dvorkin et al.'s approach against from Simm's approach of Amokura-1 well. The color bar shows the gamma ray log.

According to these figures, there are no significant differences between the results from Dvorkin et al.'s and Simm's approaches. Both predictions gave similar results and good fit with each other for Moki formation in both field. 


\section{Results \& Discussion}

Petrophysical analysis and rock physics modelling were applied to the Moki formation in Taranaki Basin. This work consists of conventional petrophysical analysis and sonic response determination from empirical relations, rock physics modelling, and fluid substitution.

The petrophysical analysis includes crossplot analysis, conventional 3-mineral identification approach, and determination of water saturation profile. Three different crossplots were prepared to specify visual description of lithology: neutron-density, matrix volumetric factor-dry grain density, and photoelectric absorption-density crossplots. These crossplots reveal that sandstone, shale, and small amount of limestone are presented together in the Moki formation. Shale is composed of clay and silt. Although these crossplots gave similar trend for each field, there were some distinctions. When we compared the crossplot results of each field based on the locations of the wells, depth range of the formation in the wells, and the points in the crossplots, we concluded that Tui Field is in an area where the subsidence occurred at faster rates or/and has a well-sorted grain size distribution; therefore, porosity remains high in the greater depths in there. Furthermore, different types of clay are presented in these two fields: illite in the Maari Field and chlorite in the Tui Field. In order to calculate the fraction of the constituting minerals, conventional 3-mineral identification approach was performed. The last step in the petrophysical analysis is determination of water saturation profile which was computed by using dual-water model. In this thesis, the water saturation profile was used as an input parameter in fluid substitution part. 
Sonic responses were predicted from two different approaches: empirical relations and rock physics model. The first empirical relation is Wyllie's Time Average equation which was used for the prediction of P-wave velocity. The equation was modified by taking into account shale and calcite as a separate matrix in addition to quartz. The P-wave velocity was calculated by using transit times of each constituting minerals and their fractions. Wyllie's Time Average equation is affected by shaliness. The equation predicts higher Pwave velocity in the layer containing significant amount of shale. Furthermore, porosity has an essential role on the equation. Higher porosity records in the Tui Field causes to predict lower P-wave velocity from the equation. The second empirical relation is Greenberg-Castagna relation which was used for the prediction of S-wave velocity. In this study, due to the absence of the recorded S-wave log, the relation results were compared with only rock-physics model results; therefore, it is not beneficial for lithology identification. The Kuster-Toksoz rock physics model was used to predict both P-wave and S-wave velocities of the Moki formation. The model is associated with the effect of clay content and pore aspect ratios of sand and clay part in the mixture. We tried a range of pore aspect ratios for sand and clay part, separately. Then we chose the couple of the aspect ratios that gave the best sonic prediction fit with the observed P-wave velocity based on the minimum RMS error. The minimum RMS error was found using the aspect ratios between 0.15 and 0.2 for sand-related pores and between 0.10 and 0.15 for clay-related pores for all wells. Kuster-Toksoz model optimizes parameters to obtain best fit the observed P-wave velocity derived from sonic log; therefore, the model works better in shale and shale-free sediments. 
Gassmann's equation was modified by using effective porosity to apply fluid substitution and estimate sonic velocities of it in shaley sediment. Two different alternative fluid substitution methods were performed to predict sonic velocities and compared the methods with each other. Since there is no recorded S-wave logs, an approximate Vp-only fluid substitution method was used. The method uses the compressional-wave modulus instead of bulk modulus. Both approaches reveal similar results. When we replaced the hydrocarbon with gas, as expected, substituted P-wave velocity and density decreased because gas has lower bulk modulus and density value than oil. On the other hand, when we replaced the hydrocarbon with water, substituted P-wave velocity and density increased because water has higher bulk modulus and density value than oil. The results from Dvorkin et al.'s and Simm's approaches show similar trends for Moki formation. 


\section{Conclusion}

In order to obtain the mineral composition and their fractions and explain the lithology changes through the depth differences, three different crossplots were prepared for the selected wells: NPHI-RHOB, UMA-DGA, and PEF-RHOB. Firstly, these crossplots indicates that Moki Formation consists of sandstone and shale which reflects combination of clay and silt with a small amount of limestone in both fields. Secondly, crossplot analysis reveals that Moki Formation is less compacted or/and well-sorted grain size distribution in the Tui Field than in the Maari Field although the formation is located at greater depths in the Tui Field. Thirdly, we may conclude that these two fields have different types of clay on a basis of crossplot analysis.

In the Maari Field, while Wyllie's Time Average equation gives good results in shale-free sediments, it predicts higher P-wave velocities in shale because of the bound water in shale structure. In the Tui Field, contrarily, Wyllie's Time Average equation predicts lower Pwave velocities than P-wave velocities derived from sonic log because of the higher porosity readings. On the other hand, Kuster-Toksoz model works better in shale and shalefree sediments because the model optimizes parameters to obtain best fit the observed Pwave velocity derived from sonic log; therefore, the model works better in both fields.

In the Maari Field, the Kuster-Toksoz model consistently predicts a higher S-wave velocity than the Greenberg and Castagna's relation except in the highest-velocity streaks where limestone is likely present because water-saturated rock properties were used for KusterToksoz model. In the Tui Field, there are no significant differences between the results from empirical relations and rock physics model. Both predictions gave similar results for 
this well. In this study, because there is no recorded S-wave velocity, the comparisons are not reliable.

There are no significant differences between the results from Dvorkin et al.'s and Simm's approaches for fluid substitution in shaley-sand. These two predictions gave similar results and good fit with each other for Moki formation in both field. 


\section{References}

Adcock, S. (1993), In search of the well tie; what if I don't have a sonic log?, The leading Edge, 12(12), 1161-1164, doi: 10.1190/1.1436929

Archie, G.E. (1942), The electrical resistivity log as an aid in determining some reservoir characteristics, Petroleum Transactions of AIME, 146: 54-62, doi: 10.2118/942054-g

Dvorkin, J., G. Mavko, and B. Gurevich (2007), Fluid substitution in shaley sediment using effective porosity: Geophysics, 72, O1-O8

Gassmann, F. (1951), Uber die Elastizität Poröser Medien: Vier. der Natur. Gesellschaft in Zürich 96, 1-23

Greenberg, M. L. and J. P. Castagna (1992), Shear-wave velocity estimation in porous rocks: Theoretical formulation, preliminary verification and applications: Geophysical Prospecting, 40, 195-209

Google Maps (2016), Field Location map. Retrieved from https://www.google.com/maps/@-41.6813217,172.1883026,898683m/data=!3m1!1e3

Hill, R. (1952), The elastic behavior of a crystalline aggregate: Proceedings of the Physical Society, Section A, Volume 65, Issue 5, pp. 349-354 (1952).

Islam, N. (2011), Sonic log prediction in carbonates, Master's Thesis, Michigan Technological University, 2011

Jordan J. R. and F. L. Campbell (1986), Well Logging II - Electric and Acoustic Logging: SPE Monograph Series, SPE, Dallas, TX

Keys, R. G. and S. Xu (2002), An approximation for the Xu-White velocity model, Geophysics, 67, 1406-1414

King, P.R., and G.P. Thrasher (1996), Cretaceous-Cenozzoic geology and petroleum systems of the Taranaki Basin, New Zealand. Institute of Geological and Nuclear Sciences monography $13.243 \mathrm{pp}$

Kuster, G. T., and M. N. Toksöz (1974), Velocity and attenuation of seismic waves in twophase media: Part1: Theoretical formulation: Geophysics, Geophysics 39, 587-606 
Mavko G, T. Mukerji, and J. Dvorkin (2003), The rock physics handbook: Tools for seismic analysis in porous media. Cambridge University Press,

Miller, S. L. M. and R. R. Stewart (1990), Effect of lithology, porosity and shaliness on Pand S-wave velocities from sonic logs: Canadian Journal of Exploration Geophysics, Vol. 26, Nos 1\&1, P. 94-103

Simm, R. (2007), Practical Gassmann fluid substitution in sand/shale sequences: First Break, 25, 61-68

$\mathrm{Xu}, \mathrm{S}$., and R. E. White (1995), A new velocity model for clay-sand mixtures: Geophysical Prospecting, 43, no. 1, 91-118

Wyllie, M. R. J., Gregory, A. R. \& Gardner, G. H. F. 1958. An experimental investigation of factors affecting elastic wave velocities in porous media. Geophysics, 23: 459-93 


\section{Appendices}

\subsection{Appendix (I)}

$$
\begin{aligned}
& V S H G R=\frac{G R-G R c l}{G R s h l-G R c l} \\
& P H I D=\frac{R H O m a-R H O B}{R H O m a-R H O f} \\
& P H I A=\frac{P H I D+N P H I}{2} \\
& U=P E F * \frac{R H O B+0.1883}{1.0704} \\
& U M A=\frac{U-U f * P H I A}{1-P H I A} \\
& D G A=\frac{R H O B-\text { RHOf } * \text { PHIA }}{1-\text { PHIA }}
\end{aligned}
$$

Where

$V S H G R=$ Shale Volume

$G R=$ Gamma ray (from logging data)

$G R c l=$ Gamma ray value for shale free lithology (We used 15 API for Moki-1 well, 45 API for Amokura-1 well)

$G R s h l=$ Gamma ray value for $100 \%$ shale (We used 75 API for Moki-1 well, 105 API for Amokura-1 well) 
$P H I D=$ Density porosity $(\mathrm{v} / \mathrm{v})$

$R H O B=$ Bulk density from logging data $\left(\mathrm{g} / \mathrm{cm}^{3}\right)$

RHOma $=$ Matrix density (We used $2.65 \mathrm{~g} / \mathrm{cm}^{3}$ )

$R H O f=$ Pore fluid density (We used $1.00 \mathrm{~g} / \mathrm{cm}^{3}$ )by assuming water in pores)

$P H I A=$ Average porosity of neutron and density porosities $(\mathrm{v} / \mathrm{v})$

$N P H I=$ Neutron porosity from logging data $(\mathrm{v} / \mathrm{v})$

$P E F=$ Photoelectric absorption factor from logging data (BE)

$U=$ Photoelectric volumetric factor $\left(\mathrm{b} / \mathrm{cm}^{3}\right)$

$U f=$ Pore fluid volumetric factor (We used $0.398 \mathrm{~b} / \mathrm{cm}^{3}$ by assuming water in pores)

$U M A=$ Apparent matrix photoelectric volumetric factor $\left(\mathrm{b} / \mathrm{cm}^{3}\right)$

$D G A=$ Apparent grain density $\left(\mathrm{g} / \mathrm{cm}^{3}\right)$ 


\subsection{Appendix (II)}

\section{Conventional 3-Mineral Identification}

In order to determine fractions of the constituting minerals, conventional 3-mineral identification method is used. For the method, the gamma ray log, density log, neutron $\log$, and photoelectric absorption log were required.

$U M A=F 1 * U 1+F 2 * U 2+F 3 * U 3$

$D G A=F 1 * D 1+F 2 * D 2+F 3 * D 3$

$F 1+F 2+F 3=1$

These three equations are mutually solved to determine the fractions of the constituting minerals: limestone, sandstone, and shale. U, D, and F symbolize photoelectric volumetric factor, dry grain density, and fractions of the constituting minerals with respectively.

$\mathrm{U} 1=$ Limestone's photoelectric volumetric factor (We used $13.776 \mathrm{~b} / \mathrm{cm}^{3}$ )

$\mathrm{U} 2=$ Sandstone's photoelectric volumetric factor $\left(\right.$ We used $\left.4.88 \mathrm{~b} / \mathrm{cm}^{3}\right)$

$\mathrm{U} 3$ = Clay's photoelectric volumetric factor $\left(\right.$ We used $\left.10 \mathrm{~b} / \mathrm{cm}^{3}\right)$

D1 = Limestone's dry grain density (We used $\left.2.71 \mathrm{~g} / \mathrm{cm}^{3}\right)$

D2 = Sandstone's dry grain density (We used $\left.2.65 \mathrm{~g} / \mathrm{cm}^{3}\right)$

D3 = Clay's dry grain density (2.92 g/ $\mathrm{cm}^{3}$ for Moki-1 well, 3.05 for Amokura-1 well)

$\mathrm{F} 1=$ Limestone fraction $(\mathrm{v} / \mathrm{v})$

$\mathrm{F} 2=$ Sandstone fraction $(\mathrm{v} / \mathrm{v})$

$\mathrm{F} 3=$ Shale fraction $($ Determined from gamma ray $\log )(\mathrm{v} / \mathrm{v})$ 


\subsection{Appendix (III)}

In order to calculate water saturation profile, the dual-water model was performed by using the deep lateralog, shallow lateralog, neutron log, and density log.

$$
\begin{aligned}
& R t=1.7 * L L D-0.7 * L L S \\
& C=\frac{V S H G R *(1-P H I A)}{1-P H I_{\text {clay }}}
\end{aligned}
$$

$$
R w b=R s h * P_{\text {clay }}^{2}
$$$$
R w a=R t * P H I A^{m}
$$

$$
S W B=\frac{P H I_{\text {clay }} * C}{P H I A}
$$

$b=S W B * \frac{1-\frac{R w}{R w b}}{2}$

$$
S W=b+a *\left(b^{2}+\frac{R w}{R w a}\right)^{1 / n}
$$$$
S H=1-S W
$$$$
P H I_{\text {eff }}=P H I A-P H I_{\text {clay }} * C
$$$$
S W_{e f f}=1-P H I A * \frac{1-S W}{P H I E}
$$

$S H_{e f f}=1-S W_{e f f}$ 
Where

$\mathrm{Rt}=$ True resistivity (ohm.m) (The formula was obtained from well reports)

LLD = Deep Lateralog from logging data (ohm.m)

LLS $=$ Shallow Lateralog from logging data (ohm.m)

$\mathrm{C}=$ The volume occupied by the porous clay $(\mathrm{v} / \mathrm{v})$

VSHGR $=$ Shale volume determined from gamma ray $\log (\mathrm{v} / \mathrm{v})$

PHIA $=$ Average porosity of neutron and density porosities $(\mathrm{v} / \mathrm{v})$

$\mathrm{PHI}_{\text {clay }}=$ The intrinsic porosity of clay $(\mathrm{v} / \mathrm{v})$

$\mathrm{Rsh}=$ Shale resistivity form nearby shale formation (ohm.m)

$\mathrm{Rwb}=$ The bound-water resistivity from nearby shale formation (ohm.m)

Rwa $=$ Apparent water resistivity of shaly sand (ohm.m)

$\mathrm{a}=\mathrm{A}$ constant determined from pickett plot

$\mathrm{m}=$ Cementation factor determined from pickett plot

$\mathrm{n}=$ Saturation exponent determined from pickett plot

$\mathrm{Rw}=$ Free water resistivity determined from pickett plot (ohm.m)

$\mathrm{SWB}=$ Bound water fraction $(\mathrm{v} / \mathrm{v})$

$\mathrm{SW}=$ Water saturation $(\mathrm{v} / \mathrm{v})$

$\mathrm{SH}=$ Hydrocarbon saturation $(\mathrm{v} / \mathrm{v})$

$\mathrm{PHI}_{\text {eff }}=$ Effective porosity $(\mathrm{v} / \mathrm{v})$

$\mathrm{SW}_{\text {eff }}=$ Effective water saturation $(\mathrm{v} / \mathrm{v})$

$\mathrm{SH}_{\mathrm{eff}}=$ Effective hydrocarbon saturation $(\mathrm{v} / \mathrm{v})$ 


\subsection{Appendix (IV)}

\section{Wyllie's Time-Average Equation}

$$
\begin{aligned}
& D T=D T m a *(1-P H I A)+D T f * P H I A \\
& D T m a=D T_{\text {calcite }} * V_{\text {calcite }}+D T_{\text {quartz }} * V_{\text {quartz }}+D T_{\text {shale }} * V_{\text {shale }} \\
& V p=\frac{304.8}{D T}
\end{aligned}
$$

$\mathrm{DT}=$ Sonic transit time $(\mu \mathrm{sec} / \mathrm{ft})$

$\mathrm{DTma}=$ Sonic transit time in matrix $(\mu \mathrm{sec} / \mathrm{ft})$

$\mathrm{DTf}=$ Fluid transit time $(\mu \mathrm{sec} / \mathrm{ft})$

$\mathrm{DT}_{\text {calcite }}=$ Calcite transit time $(\mu \mathrm{sec} / \mathrm{ft})$

$\mathrm{DT}_{\text {quartz }}=$ Quartz transit time $(\mu \mathrm{sec} / \mathrm{ft})$

$\mathrm{DT}_{\text {shale }}=$ Shale transit time $(\mu \mathrm{sec} / \mathrm{ft})$

$\mathrm{V}_{\text {calcite }}=$ Limestone fraction $(\mathrm{v} / \mathrm{v})$

$\mathrm{V}_{\text {quartz }}=$ Sandstone fraction $(\mathrm{v} / \mathrm{v})$

$\mathrm{V}_{\text {shale }}=$ Shale fraction $($ Determined from gamma ray log) $(\mathrm{v} / \mathrm{v})$

PHIA = Average porosity of neutron and density porosities (v/v)

$\mathrm{Vp}=\mathrm{P}$-wave velocity $(\mathrm{km} / \mathrm{s})$ 


\section{Greenberg and Castagna's Relation}

In order to determine shear wave velocity derived from compressional wave velocity, below equation that is depended on lithology is used.

$$
\begin{aligned}
V s= & \left(V p^{2} * a_{1}+V p * a_{2}+a_{3}\right) * V_{\text {sandstone }}+\left(V p^{2} * a_{1}+V p * a_{2}+a_{3}\right) \\
& * V_{\text {limestone }} \\
& +\left(V p^{2} * a_{1}+V p * a_{2}+a_{3}\right) * V_{\text {shale }}
\end{aligned}
$$

$V p=$ Compressional wave velocity $(\mathrm{km} / \mathrm{s})$

$V s=$ Shear wave velocity $(\mathrm{km} / \mathrm{s})$

$V_{\text {sandstone }}=$ Sandstone fraction $(\mathrm{v} / \mathrm{v})$

$V_{\text {limestone }}=$ Limestone fraction $(\mathrm{v} / \mathrm{v})$

$V_{\text {shale }}=$ Shale fraction $(\mathrm{v} / \mathrm{v})$

$\mathrm{a}_{1}, \mathrm{a}_{2}, \mathrm{a}_{3}=$ Regression coefficients which vary with lithology, shown in Table 7.1

Table 7.1. The regression coefficients for compressional-wave velocities (in $\mathrm{km} / \mathrm{s}$ ) and shear-wave velocities (in $\mathrm{km} / \mathrm{s}$ ) in pure porous matrix.

\begin{tabular}{|c|c|c|c|}
\hline Lithology & Sandstone & Limestone & Shale \\
\hline $\mathrm{a}_{1}$ & 0 & -0.05508 & 0 \\
\hline $\mathrm{a}_{2}$ & 0.80416 & 1.01677 & 0.76969 \\
\hline $\mathrm{a}_{3}$ & -0.85588 & -1.03049 & -0.86735 \\
\hline
\end{tabular}




\subsection{Appendix (V)}

$R M S=\sqrt{\frac{\sum_{i=1}^{n}\left(V p_{\text {predicted }}(i)-V p_{\text {observed }}(i)\right)^{2}}{n}}$

RMS $=$ Root mean square error $(\mathrm{km} / \mathrm{sec})$

$\mathrm{n}=$ Number of depth range

For the whole depth range, RMS error was calculated to find minimum one. 


\subsection{Appendix (VI)}

\section{Kuster-Toksoz Model (1974)}

In order to predict sonic velocities, Kuster-Toksoz model uses the elastic properties, the porosities, and the aspect ratios of two different mineral components in the matrix. The elastic properties of the matrix were calculated by using Voigt-Reuss-Hill. The average porosity of the neutron and density porosities was used in the calculations. The mineral fractions were determined by using conventional 3-mineral identification method.

$$
\begin{aligned}
& K_{e f f}=\frac{K+\frac{(4 / 3) \mu\left(K^{\prime}-K\right) T}{3 K+4 \mu}}{1-\frac{\left(K^{\prime}-K\right) T}{3 K+4 \mu}} \\
& \mu_{e f f}=\frac{\mu+\frac{\left(\mu^{\prime}-\mu\right)(9 K+8 \mu) F}{25(3 K+4 \mu)}}{1-\frac{6\left(\mu^{\prime}-\mu\right)(K+2 \mu) F}{25 \mu(3 K+4 \mu)}} \\
& V_{p}=\sqrt{\frac{K_{e f f}+(4 / 3) * \mu_{e f f}}{R H O B}} \\
& V_{s}=\sqrt{\frac{\mu_{e f f}}{R H O B}}
\end{aligned}
$$


Where

$V_{p}=$ Compressional wave velocity $(\mathrm{km} / \mathrm{s})$

$V_{s}=$ Shear wave velocity $(\mathrm{km} / \mathrm{s})$

$K_{\text {eff }}=$ The effective bulk moduli of the matrix (GPa)

$\mu_{e f f}=$ The effective shear moduli of the matrix $(\mathrm{GPa})$

$R H O B=$ Bulk density from logging data $\left(\mathrm{g} / \mathrm{cm}^{3}\right)$

$K=$ The bulk moduli of the matrix $(\mathrm{GPa})$

$K^{\prime}=$ The bulk moduli of the pore fluid $(\mathrm{GPa})$

$\mu=$ The shear moduli of the matrix (GPa)

$\mu^{\prime}=$ The shear moduli of the fluid (GPa)

$T$ and $F=$ Pore aspect ratio functions

$T=\sum_{l=s, c} P H I_{l} * T_{i i j j}\left(\alpha_{l}\right)$

$F=\sum_{l=s, c} P H I_{l} * F\left(\alpha_{l}\right)$

$P H I A=P H I_{S}+P H I_{C}$

$\mathrm{PHI}_{S}=V_{S} * \frac{P H I A}{1-P H I A}$

$P H I_{c}=V_{c} * \frac{P H I A}{1-P H I A}$ 
Where

$P H I A=$ Average porosity of neutron and density porosities $(\mathrm{v} / \mathrm{v})$

$P H I_{S}=$ The porosity of the matrix v/v)

$P H I_{c}=$ The porosity of the clay $(\mathrm{v} / \mathrm{v})$

$V_{S}=$ The volume of the matrix $(\mathrm{v} / \mathrm{v})$

$V_{c}=$ The volume of the clay $(\mathrm{v} / \mathrm{v})$

$\alpha=$ Aspect ratio of the inclusion

$T_{i i j j}(\alpha)=\frac{3 F_{1}}{F_{2}}$

$F(\alpha)=\frac{2}{F_{3}}+\frac{1}{F_{4}}+\frac{F_{4} * F_{5}+F_{6} * F_{7}-F_{8} * F_{9}}{F_{2} * F_{4}}$

Where

$$
\begin{aligned}
& F_{1}=1+A\left[\frac{3}{2}(g+\theta)-R\left(\frac{3}{2} g+\frac{5}{2} \theta-\frac{4}{3}\right)\right] \\
& F_{2}=1+A\left[1+\frac{3}{2}(g+\theta)-\frac{R}{2}(3 g+5 \theta)\right]+B(3-4 R) \\
& +\frac{A}{2}(A+3 B)(3-4 R)\left[g+\theta-R\left(g-\theta+2 \theta^{2}\right)\right] \\
& F_{3}=1+\frac{A}{2}\left[R(2-\theta)-\frac{1+\alpha^{2}}{\alpha^{2}} * g *(R-1)\right]
\end{aligned}
$$




$$
\begin{aligned}
& F_{4}=1+\frac{A}{4}[3 \theta+g-R(g-\theta)] \\
& F_{5}=A\left[R\left(g+\theta-\frac{4}{3}\right)-g\right]+B \theta(3-4 R) \\
& F_{6}=1+A[1+g-R(\theta+g)]+B(1-\theta)(3-4 R) \\
& F_{7}=2+\frac{A}{4}[9 \theta+3 g-R(5 \theta+3 g)]+B \theta(3-4 R) \\
& F_{8}=A\left[1-2 R+\frac{g}{2}(R-1)+\frac{\theta}{2}(5 R-3)\right]+B(1-\theta)(3-4 R) \\
& F_{9}=A[g(R-1)-R \theta]+B \theta(3-4 R) \\
& g=\frac{\alpha^{2}}{1-\alpha^{2}}(3 \theta-2) \\
& A=\frac{\mu^{\prime}}{\mu}-1 \\
& B=\frac{1}{3}\left(\frac{K^{\prime}}{K}-\frac{\mu^{\prime}}{\mu}\right) \\
& B K+4 \mu
\end{aligned}
$$




\subsection{Appendix (VII): Joint work with Karaman (2016)}

\subsubsection{Fluid Substitution in Shaley Sediment using Effective Porosity}

(for the correction look at 7.1.2)

$$
\begin{aligned}
& V p=\sqrt{M_{\text {sat }} / R H O_{\text {sat }}} \\
& M_{\text {drye }}=M_{s e} * \frac{1-\left(1-P H I_{\text {eff }}\right) * M_{\text {wet }} / M_{s e}-P H I_{e f f} * M_{w e t} / K_{f}}{1+P H I_{e f f}-P H I_{e f f} * M_{s e} / K_{f}-M_{w e t} / M_{s e}} \\
& M_{s a t}=M_{s e} * \frac{P H I_{e f f} * M_{\text {drye }}-\left(1-P H I_{e f f}\right) * K_{f e} * M_{\text {drye }} / M_{s e}+K_{f e}}{\left(1-P H I_{e f f}\right) * K_{f e}+P H I_{e f f} * M_{s e}-K_{f e} * M_{d r y e} / M_{s e}} \\
& R H O_{s a t}=R H O B-P H I_{e f f} *\left(R H O_{f 1}-R H O_{f e}\right)
\end{aligned}
$$

Where

$V p=\mathrm{P}$-wave velocity of the rock saturated with new fluid $(\mathrm{km} / \mathrm{s})$

$M_{s e}=$ Compressional moduli of the composite, explained below (GPa)

$M_{\text {drye }}=$ Dry frame compressional moduli $(\mathrm{GPa})$

$M_{w e t}=$ Compressional moduli of the composite saturated with one fluid, obtained from log data, explained below (GPa)

$M_{\text {sat }}=$ Compressional moduli of the composite saturated with another fluid (GPa) $K_{f}=$ Bulk moduli of the fluid mixture, obtained by using saturation profile, explained below (GPa)

$K_{f e}=$ Bulk moduli of the new fluid mixture, explained below (GPa) 
$P_{H I} I_{e f}=$ Effective porosity calculated in Appendix III (v/v)

$R H O B=$ Bulk density from logging data $\left(\mathrm{g} / \mathrm{cm}^{3}\right)$

$R H O_{s a t}=$ Bulk density of the composite saturated with another fluid $\left(\mathrm{g} / \mathrm{cm}^{3}\right)$

$R H O_{f 1}=$ Density of the fluid mixture, obtained by using saturation profile, explained below $\left(\mathrm{g} / \mathrm{cm}^{3}\right)$

$\mathrm{RHO}_{f e}=$ Density of the new fluid mixture, obtained by using saturation profile, explained below $\left(\mathrm{g} / \mathrm{cm}^{3}\right)$

\section{Calculation for $M_{w e t}$}

$M_{w e t}=R H O B * V p^{2}$

Where

$R H O B=$ Bulk density from logging data $\left(\mathrm{g} / \mathrm{cm}^{3}\right)$

$V p=\mathrm{P}$-wave velocity derived from sonic $\log (\mathrm{km} / \mathrm{s})$

\section{Calculations for modified solid phase}

$M_{s e}$ is calculated from Reuss-Voigt-Hill by using modulus of porous water saturated shale and quartz, shown in Table 3.3.

$$
\begin{aligned}
& K_{s e}=\frac{1}{2} *\left[\sum_{i=1}^{2} f_{s i} K_{s i}+\left(\sum_{i=1}^{2} f_{s i} K_{s i}^{-1}\right)^{-1}\right] \\
& \mu_{s e}=\frac{1}{2} *\left[\sum_{i=1}^{2} f_{s i} \mu_{s i}+\left(\sum_{i=1}^{2} f_{s i} \mu_{s i}^{-1}\right)^{-1}\right]
\end{aligned}
$$




$$
\begin{aligned}
& M_{s e}=K_{s e}+\frac{4}{3} \mu_{s e} \\
& R H O_{s e}=f_{s 1} * R H O_{s 1}+f_{s 2} * R H O_{s 2} \\
& f_{s 1}=1-f_{s 2} \\
& f_{s 2}=\frac{V S H G R}{\left(1-\text { PHI }_{\text {clay }}+P H I_{\text {clay }} * V S H G R\right)}
\end{aligned}
$$

Where

$f_{s 1}=$ The volume fraction of quartz $(\mathrm{v} / \mathrm{v})$

$f_{s 2}=$ The volume fraction of porous wet shale $(\mathrm{v} / \mathrm{v})$

$K_{s 1}=$ The bulk moduli of quartz (GPa)

$K_{s 2}=$ The bulk moduli of porous wet shale (GPa)

$\mu_{s 1}=$ The shear moduli of quartz (GPa)

$\mu_{s 2}=$ The shear moduli of porous wet shale $(\mathrm{GPa})$

$R H O_{s e}=$ Density of modified solid phase $\left(\mathrm{g} / \mathrm{cm}^{3}\right)$

$R H O_{s 1}=$ Density of quartz $\left(\mathrm{g} / \mathrm{cm}^{3}\right)$

$R H O_{s 2}=$ Density of porous wet shale $\left(\mathrm{g} / \mathrm{cm}^{3}\right)$

$V S H G R=$ Shale volume determined from gamma ray $\log (\mathrm{v} / \mathrm{v})$

$P H I_{\text {clay }}=$ The intrinsic porosity of clay $(\mathrm{v} / \mathrm{v})($ We used 0.14$)$ 


\section{Calculations for fluid mixtures}

$$
\begin{aligned}
& K_{f}=\left[S W * K_{w}^{-1}+(1-S W) * K_{H}^{-1}\right]^{-1} \\
& K_{f e}=\left[S W_{e f f} * K_{w}^{-1}+\left(1-S W_{e f f}\right) * K_{g}^{-1}\right]^{-1} \\
& R H O_{f 1}=S W * R H O_{w}+(1-S W) * R H O_{H} \\
& R H O_{s e}=S W_{e f f} * R H O_{w}+\left(1-S W_{e f f}\right) * R H O_{g}
\end{aligned}
$$

Where

$S W=$ Water saturation calculated in Appendix III (v/v)

$S W_{e f f}=$ Effective water saturation calculated in Appendix III (v/v)

$K_{w}=$ Bulk moduli of water $(\mathrm{GPa})$

$K_{H}=$ Bulk moduli of hydrocarbon $(\mathrm{GPa})$

$K_{g}=$ Bulk moduli of gas $(\mathrm{GPa})$

$R H O_{w}=$ Density of water $\left(\mathrm{g} / \mathrm{cm}^{3}\right)$

$R H O_{H}=$ Density of hydrocarbon $\left(\mathrm{g} / \mathrm{cm}^{3}\right)$

$R H O_{g}=$ Density of gas $\left(\mathrm{g} / \mathrm{cm}^{3}\right)$ 


\subsubsection{Correction for Fluid Substitution in Shaley Sediment using Effective}

\section{Porosity}

The saturated compressional moduli equation in Dvorkin et al.'s paper was corrected by using the saturated compressional moduli equation from Seismic Petrophysics course notes of Dr. Wayne Pennington. The correction starts with the following Pennington's equation and after seven steps the corrected equation was attained:

$M_{\text {sat }}=M_{\text {drye }}+\frac{\left(1-\left(M_{\text {drye }} / M_{\text {se }}\right)^{2}\right.}{P H I_{\text {eff }} / K_{f e}+\left(1-P H I_{\text {eff }}\right) / M_{\text {se }}-M_{\text {drye }} / M_{\text {se }}^{2}}$

$M_{\text {sat }}=M_{\text {drye }}+M_{\text {se }} \frac{\left(1-\left(M_{\text {drye }} / M_{\text {se }}\right)^{2}\right.}{P H I_{e f f} M_{s e} / K_{f e}+\left(1-P H I_{e f f}\right)-M_{\text {drye }} / M_{s e}}$

$M_{\text {sat }}=M_{\text {drye }}+M_{\text {se }}$

$* K_{f e} \frac{1-2 M_{\text {drye }} / M_{s e}+\left(M_{\text {drye }} / M_{s e}\right)^{2}}{\left.\left(P H I_{e f f} * M_{s e}\right)+\left(1-P H I_{e f f}\right) * K_{f e}-M_{d r y e} * K_{f e} / M_{s e}\right)}$

$M_{\text {sat }}=M_{\text {drye }}+M_{\text {se }}$

$$
* K_{f e} \frac{1-2 M_{\text {drye }} / M_{s e}+\left(M_{\text {drye }} / M_{s e}\right)^{2}}{\left.\left(P H I_{e f f} * M_{s e}\right)+\left(1-P H I_{e f f}\right) * K_{f e}-M_{d r y e} * K_{f e} / M_{s e}\right)}
$$

\footnotetext{
$M_{\text {sat }}$

$=\frac{M_{\text {drye }} P H I_{e f f} M_{s e}+M_{d r y e} K_{f e}-M_{d r y e} P H I_{e f f} K_{f e}-M_{d r y e}^{2} K_{f e} / M_{s e}+M_{s e} K_{f e}-2 M_{d r y e} K_{f e}+M_{d r y e}^{2} K_{f e} / M_{s e}}{\left.\left(P H I_{e f f} * M_{s e}\right)+\left(1-P H I_{e f f}\right) * K_{f e}-M_{d r y e} * K_{f e} / M_{s e}\right)}$
} 


$$
\begin{aligned}
& M_{s a t}=\frac{M_{d r y e} P H I_{e f f} M_{s e}-M_{d r y e} K_{f e}-M_{d r y e} P H I_{e f f} K_{f e}+M_{s e} K_{f e}}{\left.\left(P H I_{e f f} * M_{s e}\right)+\left(1-P H I_{e f f}\right) * K_{f e}-M_{d r y e} * K_{f e} / M_{s e}\right)} \\
& M_{s a t}=M_{s e} * \frac{M_{d r y e} P H I_{e f f}-\left(1+P H I_{e f f}\right) M_{d r y e} K_{f e} / M_{s e}+K_{f e}}{\left.\left(P H I_{e f f} * M_{s e}\right)+\left(1-P H I_{e f f}\right) * K_{f e}-M_{d r y e} * K_{f e} / M_{s e}\right)}
\end{aligned}
$$

There is sign differences between Dvorkin et al.'s equation and our equation. Below equations show the differences. First equation belongs to Dvorkin et al. and the second equation is corrected by using the equation from Seismic Petrophysics course notes of Dr. Wayne Pennington.

$$
\begin{aligned}
& M_{s a t}=M_{s e} * \frac{P H I_{e f f} * M_{d r y e}-\left(1-P H I_{e f f}\right) * K_{f e} * M_{d r y e} / M_{s e}+K_{f e}}{\left(1-P H I_{e f f}\right) * K_{f e}+P H I_{e f f} * M_{s e}-K_{f e} * M_{d r y e} / M_{s e}} \\
& M_{s a t}=M_{s e} * \frac{M_{d r y e} P H I_{e f f}-\left(1+P H I_{e f f}\right) M_{d r y e} K_{f e} / M_{s e}+K_{f e}}{\left.\left(P H I_{e f f} * M_{s e}\right)+\left(1-P H I_{e f f}\right) * K_{f e}-M_{d r y e} * K_{f e} / M_{s e}\right)}
\end{aligned}
$$




\subsubsection{Practical Gassmann Fluid Substitution in Sand/Shale Sequences}

$$
\begin{aligned}
& V p=\sqrt{M_{\text {sat } 2} / R H O_{\text {sat }}} \\
& M_{\text {PHIeff }}=\frac{P H I_{\text {eff }}}{\frac{1}{M_{\text {sat } 1}}-\frac{1}{M_{s e}}}-\frac{1}{\frac{1}{K_{f 1}}-\frac{1}{M_{s e}}} \\
& M_{\text {sat } 2}=\frac{1}{\frac{1}{M_{s e}}+\frac{P H I_{e f f}}{M_{P H I e f f}+\frac{M_{s e} * K_{f 2}}{M_{s e}-K_{f 2}}}} \\
& \text { RHO }_{\text {sat }}=R H O B-P H I_{e f f} *\left(R H O_{f 1}-R H O_{f 2}\right)
\end{aligned}
$$

Where

$V p=\mathrm{P}$-wave velocity of the rock saturated with new fluid $(\mathrm{km} / \mathrm{s})$

$M_{s e}=$ Compressional moduli of the composite, explained below $(\mathrm{GPa})$

$M_{P H I e f f}=$ Pore space stiffness $(\mathrm{GPa})$

$M_{\text {sat } 1}=$ Compressional moduli of the composite saturated with one fluid, obtained from log data, explained below (GPa)

$M_{\text {sat } 2}=$ Compressional moduli of the composite saturated with another fluid (GPa) $K_{f 1}=$ Bulk moduli of the fluid mixture, obtained by using saturation profile, explained below $(\mathrm{GPa})$

$K_{f 2}=$ Bulk moduli of the new fluid mixture, explained below (GPa)

$P H I_{e f f}=$ Effective porosity calculated in Appendix III (v/v) 
$R H O B=$ Bulk density from logging data $\left(\mathrm{g} / \mathrm{cm}^{3}\right)$

$R H O_{\text {sat }}=$ Bulk density of the composite saturated with another fluid $\left(\mathrm{g} / \mathrm{cm}^{3}\right)$

$R H O_{f 1}=$ Density of the fluid mixture, obtained by using saturation profile, explained below $\left(\mathrm{g} / \mathrm{cm}^{3}\right)$

$\mathrm{RHO}_{f 2}=$ Density of the new fluid mixture, obtained by using saturation profile, explained below $\left(\mathrm{g} / \mathrm{cm}^{3}\right)$

\section{Calculations for solid phase}

$M_{\text {sat } 1}$ and fluid mixture calculations are the same with the 'Fluid Substitution in Shaley Sediment using Effective Porosity' method; therefore, they will not rewritten in here.

$M_{s e}$ is calculated from Reuss-Voigt-Hill by using modulus of shale and quartz, shown in Table 3.3.

$$
\begin{aligned}
& K_{s e}=\frac{1}{2} *\left[\sum_{i=1}^{2} f_{s i} K_{s i}+\left(\sum_{i=1}^{2} f_{s i} K_{s i}^{-1}\right)^{-1}\right] \\
& \mu_{s e}=\frac{1}{2} *\left[\sum_{i=1}^{2} f_{s i} \mu_{s i}+\left(\sum_{i=1}^{2} f_{s i} \mu_{s i}^{-1}\right)^{-1}\right] \\
& M_{s e}=K_{s e}+\frac{4}{3} \mu_{s e} \\
& R H O_{s e}=f_{s 1} * R H O_{s 1}+f_{s 2} * R H O_{s 2}
\end{aligned}
$$


Where

$f_{s 1}=$ The volume fraction of quartz $(\mathrm{v} / \mathrm{v})$

$f_{s 2}=$ The volume fraction of shale obtained from gamma ray $\log (\mathrm{v} / \mathrm{v})$

$K_{s 1}=$ The bulk moduli of quartz $(\mathrm{GPa})$

$K_{s 2}=$ The bulk moduli of shale $(\mathrm{GPa})$

$\mu_{s 1}=$ The shear moduli of quartz (GPa)

$\mu_{s 2}=$ The shear moduli of shale $(\mathrm{GPa})$

$R H O_{s e}=$ Density of modified solid phase $\left(\mathrm{g} / \mathrm{cm}^{3}\right)$

$R H O_{s 1}=$ Density of quartz $\left(\mathrm{g} / \mathrm{cm}^{3}\right)$

$R H O_{s 2}=$ Density of shale $\left(\mathrm{g} / \mathrm{cm}^{3}\right)$ 


\subsection{Appendix (VIII)}

Kea-1 Well
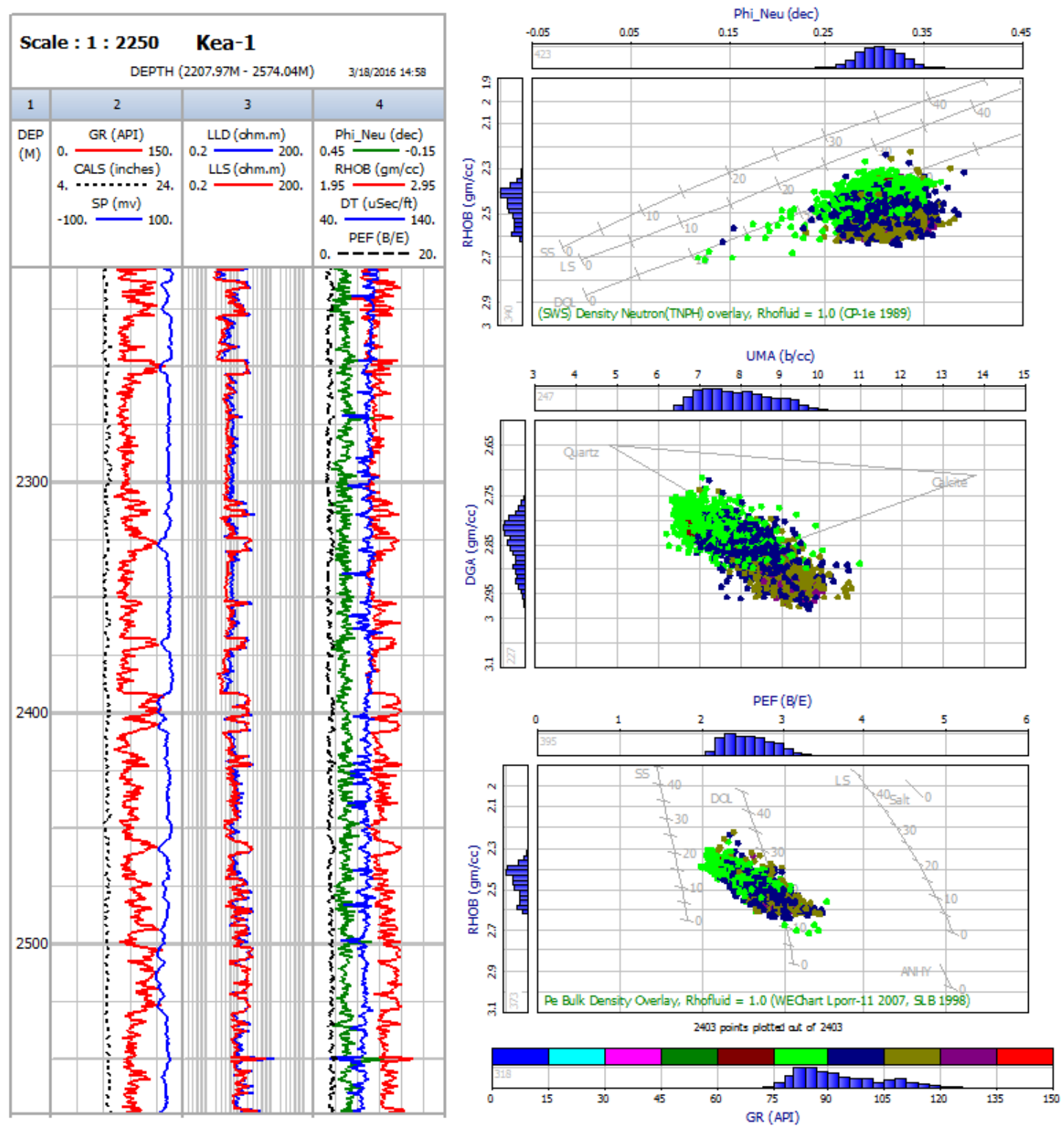

Figure 7.1.The litholog and crossplots of the Kea-1 well in Maari Field and were used to identify the mineralogy of the Moki formation in the Taranaki Basin. 


\section{Maari-1 Well}
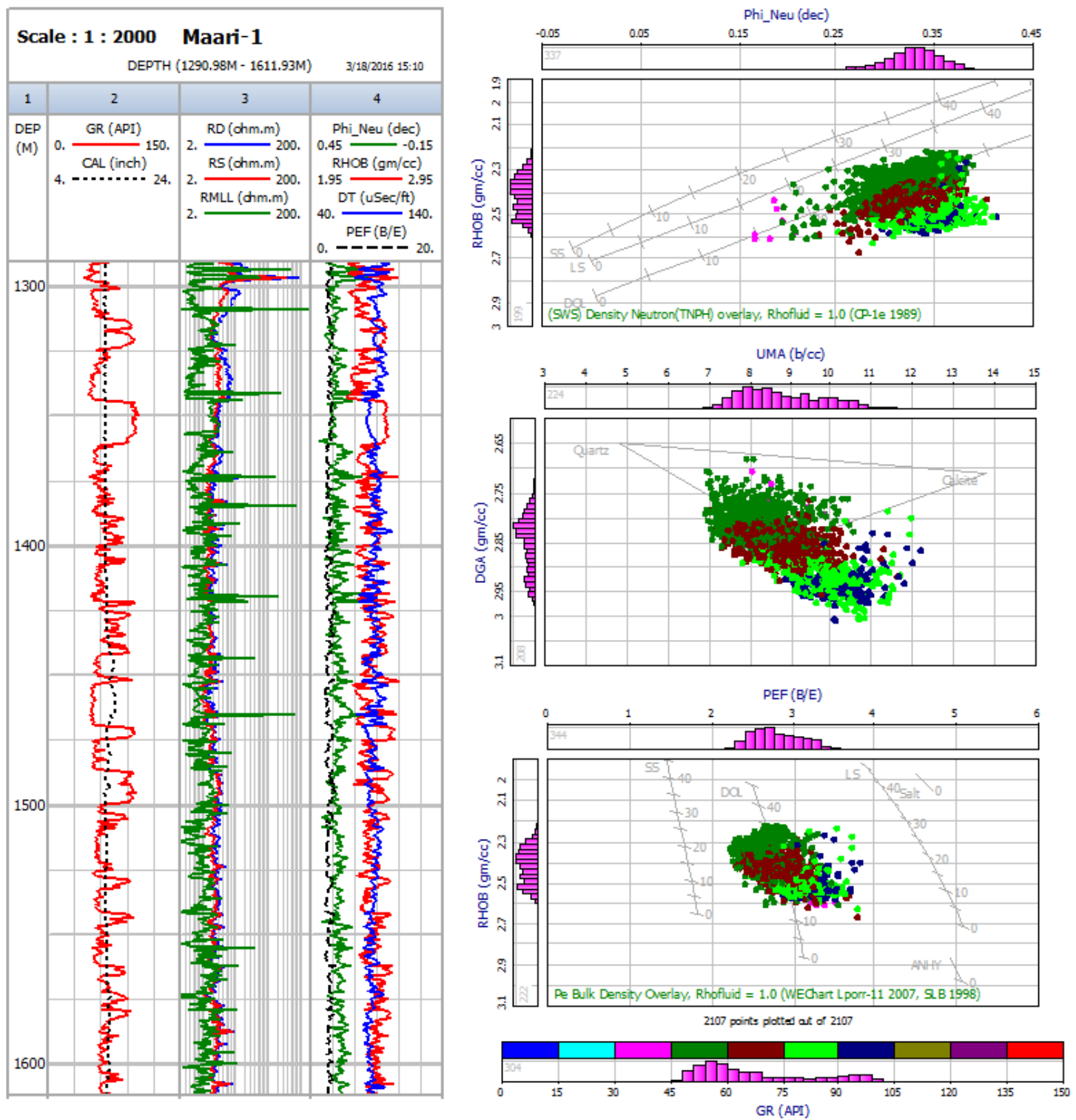

Figure 7.2.The litholog and crossplots of the Maari-1 well in Maari Field and were used to identify the mineralogy of the Moki formation in the Taranaki Basin. 


\section{Tui-1 Well}
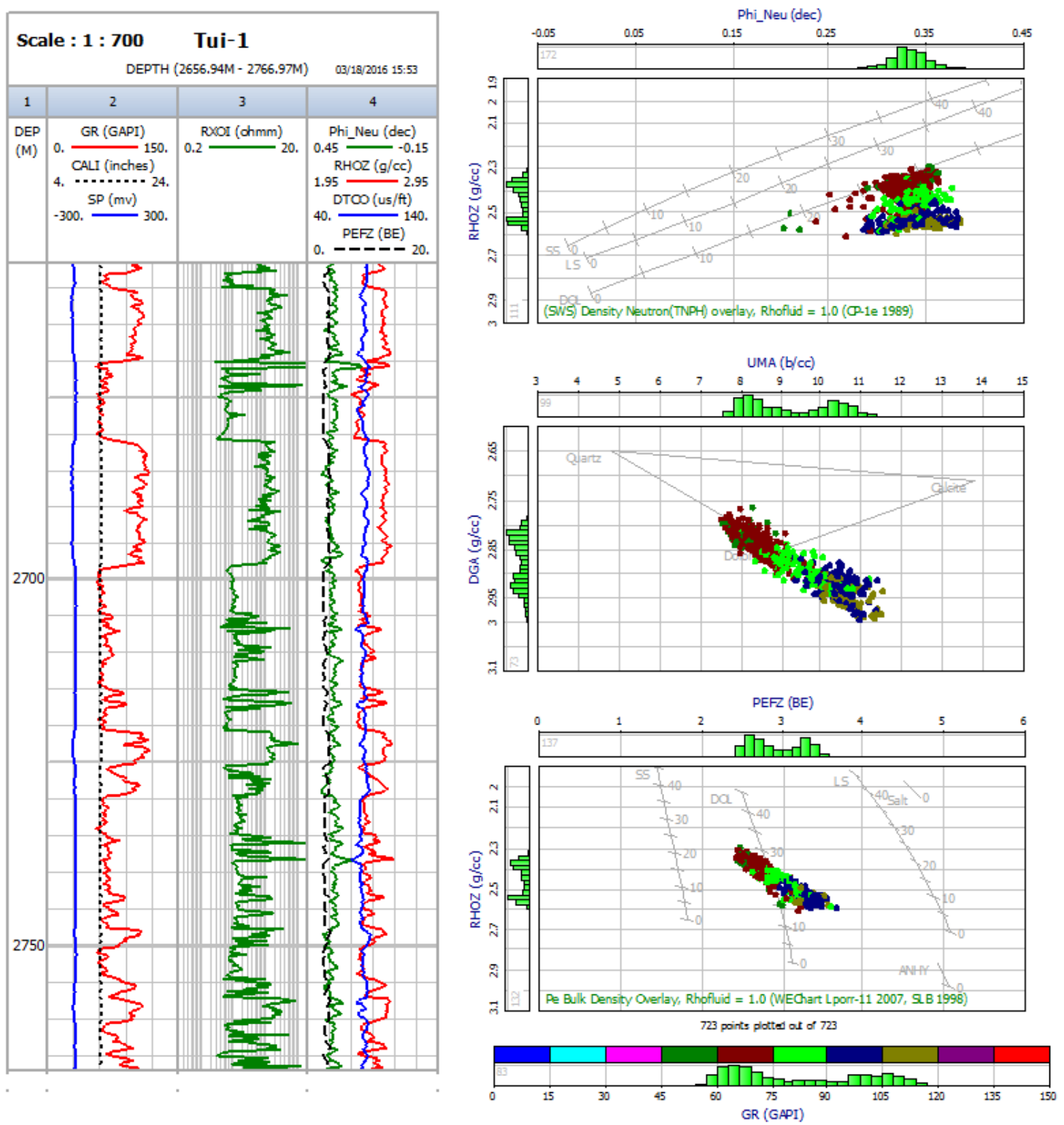

Figure 7.3.The litholog and crossplots of the Tui-1 well in Tui Field and were used to identify the mineralogy of the Moki formation in the Taranaki Basin. 


\section{Pateke-2 Well}
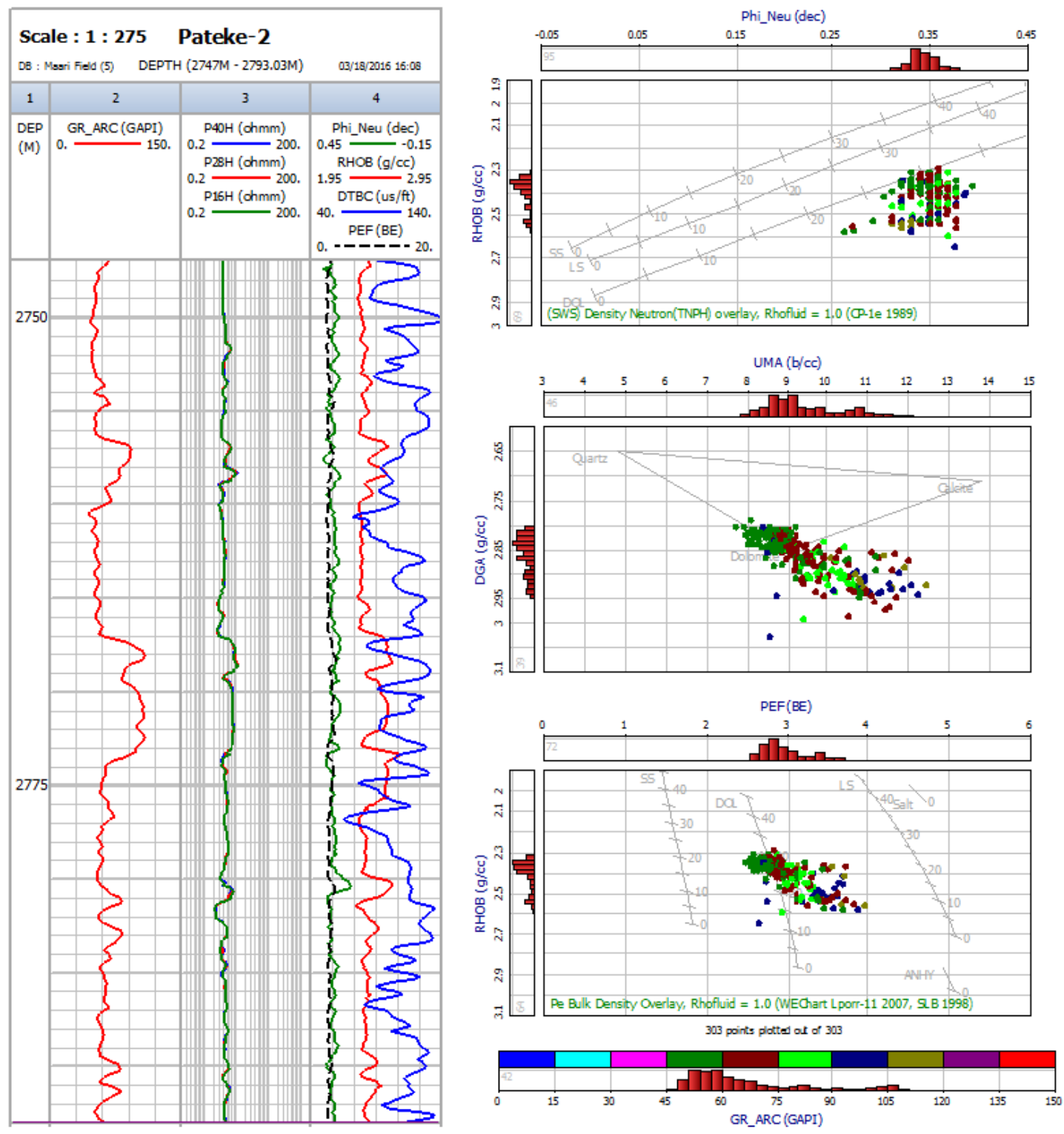

Figure 7.4.The litholog and crossplots of the Pateke-2 well in Tui Field and were used to identify the mineralogy of the Moki formation in the Taranaki Basin. 


\subsection{Appendix (IX)}

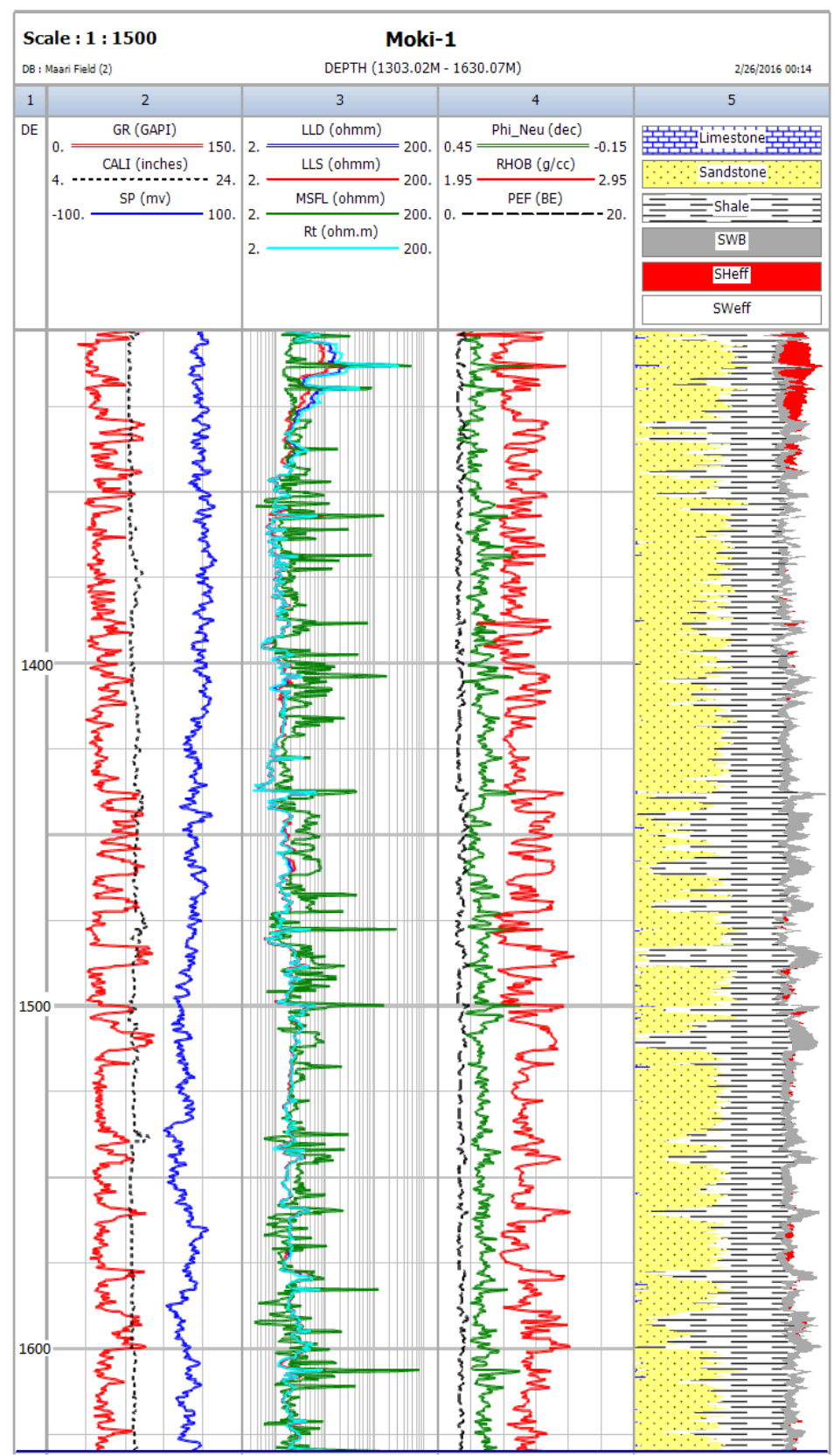

Figure 7.5. Litholog for Moki-1 well. The first track shows depth range. The second track displays gamma ray (red), caliper (black), and spontaneous potential (blue) logs. The third track displays resistivity logs: deep lateralog (blue), shallow lateralog (red), microspherically focused (green), and true resistivity (light blue) from formula. The forth track displays neutron (green), density (red), and photoelectric absorption (black) logs. The last track shows the lithology by applying 3-mineral identification approach and dual-water model. 


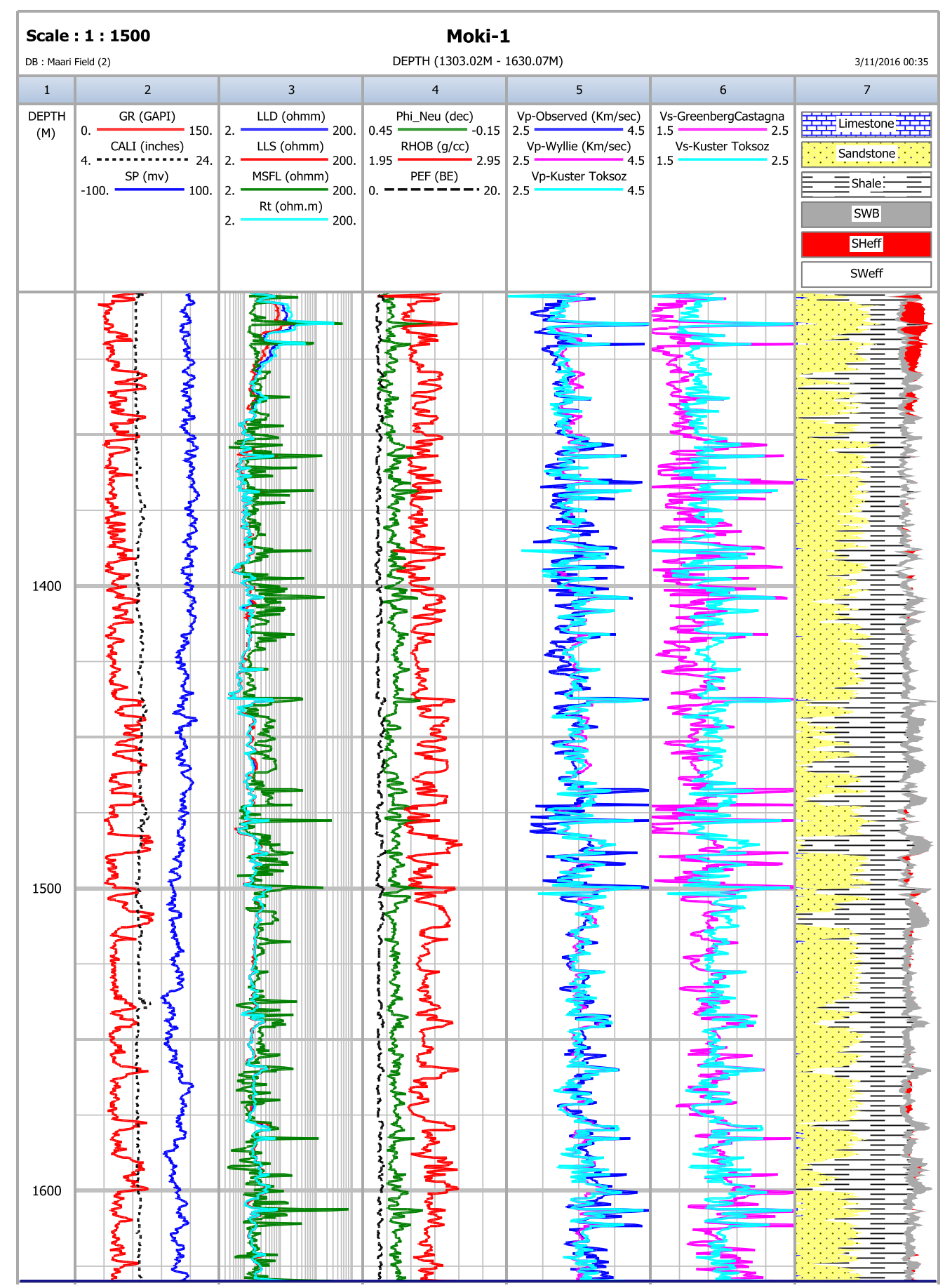

Figure 7.6. Sonic wave prediction logs for Moki-1 well. The fifth track shows the P-wave velocities: observed from sonic log (blue), predicted from Wyllie' Time Average Equation (pink) and from Kuster-Toksoz model (light blue). The sixth track displays the S-wave velocities: predicted from Greenberg-Castagna relation (pink) and from Kuster-Toksoz model (light blue). 